NASA Technical Memorandum 89853

\title{
Calibration and Comparison of the NASA Lewis Free-Piston Stirling Engine Model Predictions with RE-1000 Test Data
}

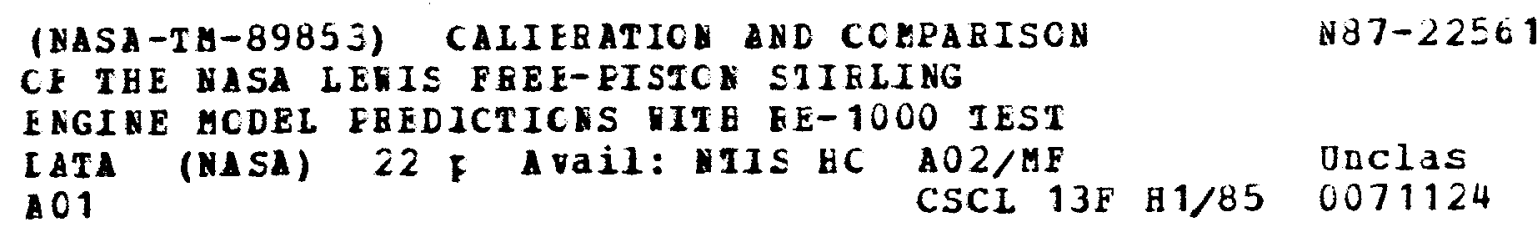

Steven M. Geng

Lewis Research Center

Cleveland, Ohio

Prepared for the

22nd Intersociety Energy Conversion Engineering Conference cosponsored by the AIAA, ANS, ASME, SAE, IEEE, ACS, and AIChE Philadelphia, Pennsylvania, August 10-14, 1987

\section{NMSก}


Steven M. Geng

National Aeronautics and Space Administration

Lewis Research Center

Cleveland, Ohio 44135

\section{Abstract}

A free-piston Stirling engine performance code is being upgraded and validated at the NASA Lewis Research Center under an interagency agreement between the Department of Energy's 0ak Ridge National Laboratory and NASA Lewis. Many modifications have been made to the free-piston code in an attempt to decrease the calibration effort. A procedure was developed that made the code calibration process more systematic. Engine-specific calibration parameters are often used to bring predictions and experimental data into better agreement. The code was calibrated to a matrix of six experimental data points. Predictions of the calibrated free-piston code are compared with RE-1000 free-piston Stirling engine sensitivity test data taken at NASA Lewis. Reasonable agreement was obtained between the code predictions and the experimental data over a wide range of engine operating conditions.

\section{Executive Summary}

A free-piston Stirling engine performance code is being upgraded and validated at NASA Lewis under an interagency agreement between the Department of Energy's Oak Ridge National Laboratory and NASA Lewis. Many modifications have been made to the free-piston code in an attempt to decrease the calibration effort required. The following changes have been made to the code: (1) heat-transfer and friction-factor correlations for the cooler and the regenerator were modified; (2) gas leak path model for the power piston was modified; (3) displacer appendix gap pumping loss equation was added; (4) option was added to separate the connecting ducts into their own control volumes; and (5) option was added to run the code with the displacer gas spring represented by either a control volume or a spring constant and damping factor.

After all the changes were made to the code, a process was developed that logically arrived at the best set of engine-specific calibration parameters. Engine-specific calibration parameters based on engine test data were used to bring predictions and experimental data into better agreement. These parameters were defined as the set of multiplication factors and coefficients required to adjust predicted pressure drops, heat transfer, and gas flow rates so that the code predictions could better agree with a specific engine's test data. The code was calibrated to a matrix of six experimental data points. Predictions of the calibrated code were compared with RE-1000 free-piston Stirling engine experimental data. Measured and predicted data that were compared include indicated power, indicated efficiency, compression space pressure amplitude, displacer stroke, pistondisplacer phase angle, piston-compression space pressure phase angle, frequency, and expansion and compression space gas temperatures. Most comparisons agreed within the error bands of the test data. The predicted indicated power and efficiency agreed within \pm 3 to \pm 11 percent of the actual test data.

More information is needed in the areas of oscillating flow heat transfer and pressure drop, leakage and centering port flow, and gas spring hysteresis loss. The ultimate goal is to have a code that does not require any engine-specific calibration parameters. Although the predictions of the code agreed fairly well with the RE-1000 test data, it is an engine-specific code. Before the code could be used to simulate a different free-piston engine with a large degree of confidence, the code would need to be calibrated for that particular engine.

\section{Nomenc lature}

Ad crosss-sectional area of displacer, in. 2 $\left(\mathrm{cm}^{2}\right)$

Adr crosss-seçtional area of displacer rod, in. $2\left(\mathrm{~cm}^{2}\right)$

A eff effective area for heat transfer on water side of cooler, in. $2\left(\mathrm{~cm}^{2}\right)$

$A_{p} \quad$ cross-seçtional area of power piston, in. $2\left(\mathrm{~cm}^{2}\right)$

C conversion factor

$C_{d s}$ damping factor of displacer gas spring, ibf-s/in. $(\mathrm{N}-\mathrm{s} / \mathrm{cm})$

D displacer diameter, in. $(\mathrm{cm})$

$D_{h} \quad$ hydraulic diameter, in. $(\mathrm{cm})$

F Fanning friction factor

$F_{B} \quad$ body force on displacer, $1 b_{f}(N)$

$\mathrm{F}_{\mathrm{d}}$ net force acting on displacer, $1 b_{f}(N)$

$F_{S}$ displacer gas spring force, $1 b_{f}(N)$

$\mathrm{H}$ heat-transfer coefficient, Btu/ft $\mathrm{ft}^{2}-\mathrm{s}^{\circ} \mathrm{R}$ $\left(\mathrm{W} / \mathrm{m}^{2}-{ }^{\circ} \mathrm{C}\right)$ or in. $-1 \mathrm{~b}_{\mathrm{f}} / \mathrm{in}^{2} \mathrm{C}_{-\mathrm{s}-{ }^{\circ} \mathrm{R}\left(\mathrm{W} / \mathrm{cm}^{2}-{ }^{\circ} \mathrm{C}\right)}$

h radial clearance between displacer and displacer cylinder, in. $(\mathrm{cm})$

$K_{d s} \quad$ spring constant of displacer gas spring, $\mathrm{lb}_{\mathrm{f}} / \mathrm{in}$. $(\mathrm{N} / \mathrm{cm})$

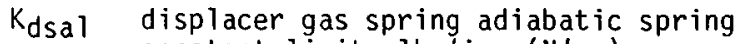
constant limit, $1 b_{f} / i n$. $(\mathrm{N} / \mathrm{cm})$

$\mathrm{kag}$ thermal conductivity of gas in appendix gap, Btu/in.-s- $R\left(W / \mathrm{cm}^{\mathrm{B}} \mathrm{C}\right)$

$k_{a} l$ thermal conductivity of aluminum, Btu/in.-s- R (W/cm- C) 


\begin{tabular}{|c|c|c|c|}
\hline$k_{r}$ & $\begin{array}{l}\text { thermal conductivity of gas in regenerator, } \\
\text { in.-lb } b_{f} / \text { in. }-s-R(W / c m-C)\end{array}$ & $v_{\text {do }}$ & $\underset{\left(\mathrm{cm}^{3}\right)}{\operatorname{mean} \text { displacer gas spring volume, in. } 3}$ \\
\hline $\mathrm{k}_{\mathrm{sS}}$ & $\begin{array}{l}\text { thermal conductivity of stainless steel } \\
\text { displacer, Btu/in. }-\mathrm{s}^{\circ} \mathrm{R}\left(\mathrm{W} / \mathrm{Cm}-{ }^{\circ} \mathrm{C}\right)\end{array}$ & $V_{p}$ & $\begin{array}{l}\text { amplitude of the piston velocity, in./s } \\
(\mathrm{cm} / \mathrm{s})\end{array}$ \\
\hline$k_{W}$ & $\begin{array}{l}\text { thermal conductivity of water, } B t u / f t-s-{ }^{\circ} R \\
\left(\mathrm{~W} / \mathrm{m}-{ }^{\circ} \mathrm{C}\right)\end{array}$ & $x_{d}$ & amplitude of displacer stroke, in. $(\mathrm{cm})$ \\
\hline L & length of cooler tubes, in. (cm) & $x_{d}$ & $\begin{array}{l}\text { instantaneous position of displacer, in. } \\
(\mathrm{cm})\end{array}$ \\
\hline$M_{d}$ & mass of displacer, slugs $(\mathrm{kg})$ & $\dot{x}_{\mathrm{d}}$ & $\begin{array}{l}\text { instantaneous velocity of displacer, in. } / \mathrm{s} \\
(\mathrm{cm} / \mathrm{s})\end{array}$ \\
\hline$\Delta P$ & $\begin{array}{l}\text { range of expansion space pressure, psi } \\
\left(\mathrm{N} / \mathrm{cm}^{2}\right)\end{array}$ & $\ddot{x}_{d}$ & $\begin{array}{l}\text { instantanequs acceleration of displacer, } \\
\mathrm{ft} / \mathrm{s}^{2}\left(\mathrm{~m} / \mathrm{s}^{2}\right)\end{array}$ \\
\hline$P_{B}$ & mean bounce space pressure, psi $\left(\mathrm{N} / \mathrm{cm}^{2}\right)$ & $x_{p}$ & amplitude of piston stroke, in. $(\mathrm{cm})$ \\
\hline$P_{C}$ & $\begin{array}{l}\text { mean compression space pressure, psi } \\
\left(\mathrm{N} / \mathrm{cm}^{2}\right)\end{array}$ & $x_{p}$ & instantaneous position of piston, in. (cm) \\
\hline$P_{c a}$ & $\begin{array}{l}\text { compression space pressure amplitude, psi } \\
\left(\mathrm{N} / \mathrm{cm}^{2}\right)\end{array}$ & $\alpha$ & $\begin{array}{l}\text { thermal diffusivity of displacer, in. } 2 / \mathrm{s} \\
\left(\mathrm{cm}^{2} / \mathrm{s}\right)\end{array}$ \\
\hline$P_{D}$ & $\begin{array}{l}\text { mean displacer gas spring pressure, psi } \\
\left(\mathrm{N} / \mathrm{cm}^{2}\right)\end{array}$ & $\begin{array}{l}Y \\
\theta\end{array}$ & $\begin{array}{l}\text { specific heat ratio, } C_{p} / C_{v} \\
\text { phase angle between the power piston and }\end{array}$ \\
\hline$P_{d}$ & $\begin{array}{l}\text { instantaneous displacer gas spring } \\
\text { pressure, psi }\left(\mathrm{N} / \mathrm{cm}^{2}\right)\end{array}$ & & $\begin{array}{l}\text { the compression space pressure wave, deg } \\
\text { phase angle between the displacer and the }\end{array}$ \\
\hline$P_{E}$ & $\begin{array}{l}\text { mean expansion space pressure, psi } \\
\left(\mathrm{N} / \mathrm{cm}^{2}\right)\end{array}$ & & expansion space pressure wave, deg \\
\hline $\mathrm{Pr}$ & Prandt 1 number & $\psi$ & $\begin{array}{l}\text { phase angle between the compression space } \\
\text { pressure wave and the piston velocity, deg }\end{array}$ \\
\hline$p$ & regenerator porosity & $\omega$ & engine frequency, $\mathrm{Hz}$ \\
\hline $\mathrm{Q}_{\text {out }}$ & heat rejected from cooler per engine & & Introduction \\
\hline
\end{tabular}

cycle

Qpump appendix gap gas enthalpy transfer (or pumping loss), in. $-1 b_{f} / s(\mathrm{~cm}-\mathrm{N} / \mathrm{s})$

$\mathrm{R}_{\mathrm{a} 1}$ thermal resistance for conductive heat transfer in aluminum, $s-\mathrm{R} / \mathrm{Btu}\left({ }^{\circ} \mathrm{C} / \mathrm{W}\right)$

Re Reynolds number

$R_{H 20}$ thermal resistance for convective heat transfer between water and cooler wall, $\mathrm{s}-{ }^{\circ} \mathrm{R} / \mathrm{Btu}\left({ }^{\circ} \mathrm{C} / \mathrm{W}\right)$

$r_{i}$ effective radius of gas side of cooler, in. $(\mathrm{cm})$

$r_{0} \quad$ effective radius of water side of cooler, in. $(\mathrm{cm})$

$\Delta T$ temperature differential, ${ }^{\circ} \mathrm{R}\left({ }^{\circ} \mathrm{C}\right)$

$\mathrm{T}_{\mathrm{H} 20}$ cooling water inlet temperature, ${ }^{\circ} \mathrm{R}\left({ }^{\circ} \mathrm{C}\right)$

$T_{h}$ maximum temperature of gas entering the append ix gap, ${ }^{\circ} \mathrm{R}\left({ }^{\circ} \mathrm{C}\right)$

$T_{1}$ minimum temperature of gas entering the appendix gap, ${ }^{\circ}\left({ }^{\circ} \mathrm{C}\right)$

$\mathrm{T}_{\mathrm{W}}$ temperature of the cooler wall, ${ }^{\circ} \mathrm{R}\left({ }^{\circ} \mathrm{C}\right)$

Twold temperature of the cooler wall during the previous cycle, ${ }^{\circ}\left({ }^{\circ} \mathrm{C}\right)$

\section{Introduction}

A kinematic Stirling engine performance code written at NASA Lewis 1 was modified in the areas of engine thermodynamics, piston/displacer dynamics, and engine generic geometry to predict the performance of a free-piston Stirling engine. Mechanical Technology, Inc., (MTI) modified the kinematic code in 1980 under contract with NASA Lewis. Development of the free-piston code continued at NASA under an interagency agreement between NASA Lewis and the Department of Energy's Oak Ridge National Laboratory (ORNL). Under this agreement, the RE-1000 free-piston Stirling engine has been modeled and tested.

The RE-1000 was designed and built by Sunpower Inc., of Athens, Ohio. It was designed as a research tool and was obtained in 1979 for testing as part of the NASA Stirling engine technology program at Lewis. The RE-1000 is an electrically heated single-cylinder engine with a dashpot load. A cutaway view of the engine is shown in $\mathrm{Fig} .1$. The engine was tested over a wide range of heatertube outside-wall temperatures, mean working-space pressures, cooling-water inlet temperatures, piston strokes, and working fluids. In addition, tests were conducted with different engine configurations. These different configurations included two different regenerators, two displacers, and two pistons. When the engine was purchased, it was built with a regenerator and a displacer that are referred to as regenerator 1 and displacer 1 . These parts were optimized within a set of design constraints to achieve high engine efficiency. At a later time in the testing of the RE-1000, NASA Lewis purchased a regenerator and displacer from 
Sunpower that were optimized for high-power output with all other parameters of the engine held constant. These high-power parts are referred to as regenerator 2 and displacer 2 . For this report the high efficiency engine configuration was chosen and the code was calibrated. Comparisons were made between predicted and meaşured data over a range of operating conditions. 3 Regenerator 1 had a porosity of 75.9 percent while displacer 1 was designed to operate with a phase angle of about $45^{\circ}$ with respect to the power piston. The actual phase angle at engine design conditions was higher than the design phase angle, probably due to a slightly higher displacer damping than assumed during the design process. The standard piston mass gave the engine a resonant frequency of about $30 \mathrm{~Hz}$.

This report describes the modifications made to the code since the validation effort was carried out as described by Tew. 4 In addition, the approach used to calibrate the code is presented. Finally, the code predictions are compared with experimental data for the RE-1000 free-piston Stirling engine.

\section{Code Modifications}

The free-piston Stirling engine code in its previous form could predict trends in engine performance. Predicted power and efficiency were in reasonably good agreement with test data within the \pm 10 to \pm 15 percent range. In an effort to improve the code predictions, many modifications were made. These modifications are described in detail in the following paragraphs.

The first modification involved the cooler model. For the RE-1000, the cooler is a cylindrical aluminum heat exchanger which consists of 135 rectangular gas passages and 80 circular water passages. The cooler is both a parallel and counterflow type of heat exchanger depending on the instantaneous direction of the oscillating working space gas. All the passages run in an axial direction. The gas passages are located near the inner radius of the cylinder while the water passages are located near the outer radius of the cylinder as shown in Fig. 2. Previously, the gas side of the cooler was modeled using circular tube heat-transfer and friction-factor correlations.

Since the RE-1000's cooler passages have rectangular cross sections, rectangular tube heattransfer and friction-factor correlations were substituted for the circular tube correlations. Both the heat-transfer and the friction-factor correlations assume fully developed, steady flow and were obtained from Kays and London. 5 The rectangular passage heat-transfer correlation is in tabular form for a range of Reynolds numbers from 0 to 30000 . The method of linear interpolation is used for Reynolds numbers that fall between the table values. The friction factor correlations for the gas side of the cooler are

$$
\begin{array}{ll}
F=\frac{20.4}{\operatorname{Re}} & R e \leq 1500 \\
F=\frac{0.046}{R e^{0.2}} & R e \geq 20000
\end{array}
$$

$F=\frac{0.079}{\operatorname{Re}^{0.25}} \quad 1500<\operatorname{Re}<20000$

The friction-factor equation for laminar flow (i.e., $\operatorname{Re}<1500$ ) is for the RE-1000's rectangular cooler passages which have an aspect ratio of 0.135 . This equation must be reviser if any changes are made to the dimensions of the cooler gas passages. The term aspect ratio is defined as

aspect ratio $=b / a$

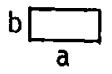

The friction-factor equations for turbulent flow are valid for any rectangular passages.

A heat-transfer correlation was added for the water side of the cooler. This correlation eliminated the need to guess the initial temperature of the cooler wall as was done previously. The cooling-water inlet temperature and flow rate, which can be accurately measured, are now used as inputs. The heat-transfer correlation for the water side of the cooler is

$H=\frac{{ }^{*} k_{w}}{D_{h}}\left[3.66+\frac{0.0668\left(D_{h} / L\right) \operatorname{RePr}}{1+0.04\left(\left(D_{h} / L\right) \operatorname{RePr}\right)^{0.666}}\right]$

where $c=12 \mathrm{in.} / \mathrm{ft}$ or $100 \mathrm{~cm} / \mathrm{m}$. This correlation assumes fully developed laminar flow in tubes with constant wall temperatures. "The heat-transfer coefficient calculated from this equation is then used in the calculation of the thermal resistance of the water side of the cooler as shown below. Also, the thermal resistance of the aluminum separating the water and the gas is calculated assuming an effective thickness of material as shown below. The effective area and the effective thickness used in the thermal resistance equations are calculated assuming solid cylinderical water and gas passages with the same flow areas of the actual water and gas passages:

$R_{H 2 O}=C \frac{1}{H A_{\text {eff }}}$

where $C=144 \mathrm{in}^{2} / \mathrm{ft}^{2}$ or $10000 \mathrm{~cm}^{2} / \mathrm{m}^{2}$ and

$R_{a l}=\frac{\ln \left(r_{0} / r_{i}\right)}{2 \pi L k_{a l}}$

After the thermal resistances are calculated, the temperature of the cooler wall on the gas side is calculated using the equations

$T_{w}=T_{H 20}+Q_{\text {out }} \omega C\left(R_{a 1}+R_{H 20}\right)$

where $C=1.0725 \times 10^{-4}$ Btu/ir.-1bf or $0.01 \mathrm{~m} / \mathrm{cm}$ and $T_{w}=0.5 T_{w}+0.5 T_{\text {wold }}$

A correction was made to the code concerning the leak path for the power piston. The previous leakage model assumed that the major leak path for the piston was from the centering port on the piston to the buffer space through the annular clearance between the piston and the cylinder as shown in Fig. 3. The new leakage model simulates the leak path between the centering port on the 
piston and the centering port on the piston cylinder. The new leak path, as shown in Fig. 3, is much shorter than the old path.

A displacer appendix gap gas enthalpy transfer (or pumping loss) equation has been added to the free-piston code. The term appendix gap refers to the small clearance space between the displacer and the displacer cylinder. The net appendix gap loss is now calculated by adding the net gas enthalpy loss to the shuttle loss. The shuttle loss is a conduction loss enhanced by the displacer's oscillatory motion and the radiation heat transfer between the displacer and cylinder walls; the net gas enthalpy loss is the heat transfer down the gap by virtue of the working gas motion, pressure, and temperature. This is illustrated in Fig. 4. The equation used for calculating the net gas enthalpy transfer was taken from Ref. 7 and is as follows:

$Q_{\text {pump }}=\pi D \Delta P h X_{d} \omega \frac{\gamma}{\gamma-I} \ln \left(\frac{T_{h}}{T_{V}}\right)\left(\frac{1}{2}-\frac{k_{a g}}{h(\omega / 2 \alpha)^{0.5} k_{s s}}\right) \sin \phi$

The maximum temperature of the gas entering the appendix gap $T_{h}$ was assumed to be at the cylinder hot end metal temperature while the minimum temperature $T_{1}$ was assumed to be at the cylinder cold end temperature. This equation neglects the hysteresis loss that occurs in the appendix gap. In compensation, the surface area of the displacer cylinder in the appendix gap was included in the expansion space surface area for heat-transfer calculation.

The working space model consists of the swept volumes in the expansion and compression spaces, three heat exchangers (heater, regenerator, and cooler), and four connecting ducts. The heater, regenerator, and cooler are connected in series via connecting ducts between the two swept volumes. The working space is divided into a number of control volumes for analysis of fluid flow and heat transfer. Previously, the connecting duct volumes were lumped with adjacent heat exchangers or swept volumes. An option has been added to separate each connecting duct into two control volumes. The two control volume representation for the RE-1000 eliminated the need to compute effective flow areas for those connecting ducts whose flow areas are nonuniform. The connecting duct model assumes adiabatic conditions.

The regenerator heat-transfer and frictionfactor correlations were revised. Earlier correlations were for wire screen regenerators. The new correlations are for Metex, knitted-wire regenerators. The heat-transfer correlation ${ }^{8}$ and the friction-factor correlation ${ }^{3}$ were based on experimental steady-state flow data. The correlations are

$H=\frac{0.588 k_{r} p^{5.66} R e^{0.76}}{D_{h}}$

$F=12.27 R e^{-0.73} \quad \operatorname{Re}<20$

$F=4.04 R e^{-0.37} \quad 20 \leq R e \leq 85$

$F=2.19 R e^{-0.23} \quad \operatorname{Re}>85$
The last modification made to the code was on the displacer gas spring model. An option was added to run the code with the displacer gas spring represented with either a control volume or a spring constant and damping factor. Previously only the control volume representation was used. Great difficulty was experienced in matching the predicted piston-displacer phase angle with the experimental data using the control volume gas spring representation. This difficulty seems to indicate that the displacer gas spring model is inadequate. This inadequacy might be due to the improper modeling of the gas spring hysteresis loss (no phase lag between heat transfer and $\Delta T$ is accounted for). Therefore, the spring constant/ damping factor option was chosen for the comparisons made in this report. The spring constant and damping factor for the displacer gas spririg are now calculated by the code during the constrained mode of operation and are then used as inputs for the unconstrained mode. The spring constant is used in the calculation of the instantaneous pressure of the gas spring:

$P_{d}=P_{B}+\frac{K_{d s}}{A_{d r}} x_{d}$

The average pressure in the displacer gas spring is assumed to be equal to the average pressure in the bounce space. This assumption seemed reasonable since the displacer gas spring volume and the bounce space volume are in direct communication every time the centering ports open. A damping factor is used in the calculation of the net force acting on the displacer:

$F_{d}=\left(P_{E}-P_{C}\right) A_{d}+\left(P_{C}-P_{D}\right) A_{d r}+F_{B}-C_{d s} \dot{x}_{d}$

Calibration Procedure

The free-piston code can simulate three different modes of operation: (1) constrained mode, (2) semiconstrained mode, and (3) unconstrained mode. In the constrained mode, the motions of both the piston and displacer are specified. This mode of operation is useful in calibrating the engine thermodynamics. In the semiconstrained mode, the motion of the piston is specified while the displacer motion is calculated. This mode of operation is useful in calibrating the displacer dynamics. In the unconstrained mode, the motions of both the piston and the displacer are calculated. This mode of operation is useful in calibrating the piston dynamics.

\section{Calibration Parameters}

The free-piston Stirling engine code had to be calibrated for the RE-1000 engine before comparisons between predicted and experimental engine performance could be made. The code was calibrated by adjusting nine model parameters which are difficult to specify accurately from geometrical

data. These nine parameters are as follows:

FMULT pressure drop multiplication factor RHCFAC regenerator heat-transfer multiplication factor

FHEXP expansion space cylinder heat-transfer multiplication factor

FHCOMP compression space cylinder heat-transfer multiplication factor 
CPTDO

FDBLK

CPTPO

FLEAK

displacer centering port flow coefficient displacer leakage multiplication factor piston centering port flow coefficient piston leakage multiplication factor dashpot load coefficient

Note that some of the parameters are labeled factor while other parameters are labeled coefficient. The calibration parameter list contains two different subsets of parameters. The term factor refers to the subset of dimensionless calibration parameters while the term coefficient refers to the subset of calibration parameters that have physical properties. Calibration parameters are defined as the set of multiplication factors and coefficients required to adjust predicted pressure drops, heat transfer, and gas flow rates.

The pressure drop multiplication factor (FMULT) is applied to the pressure drops calculated in the cooler, regenerator, and heater. The friction factor correlations assume steady flow conditions. Oscillating flow, which is the actual flow condition in the Stirling engine, is currently poorly understood; thus, effects of oscillating flow are not included in the friction-factor (or heat-transfer) correlations.

The regenerator heat-transfer factor (RHCFAC) is applied to the regenerator heat-transfer coefficient. The regenerator heat-transfer correlation also assumes steady flow conditions. RHCFAC was added to the code when the stacked wire screen heat-transfer correlation was being used to model the regenerator. Now that the code contains a correlation for Metex regenerators, RHCFAC is probably of less importance.

The expansion and compression space cylinder heat-transfer factors (FHEXP and FHCOMP) are applied to their respective heat-transfer coefficients. Modifications of these factors adjust the cylinder hysteresis (or cyclic) losses. There is a transient heat-transfer process between the working space gas and the cylinder wall as the gas temperature is lowered and raised during the expansion and compression process. The net heat flow across this alternating temperature difference gives rise to an irreversible loss known as the hysteresis loss.

The centering port flow coefficients (CPTDO and (PTPO) are used to regulate the amount of centering port flow. They are used when the centering ports are either completely or partially open. The purpose of the centering ports is to insure that the midpoints of the strokes of the displacer and piston stay at some fixed location in the engine. The centering ports are required since the leakage past most of the seals in the engine is not symmetrical. In the configuration of the RE-1000, the displacer will drift toward the compression space while the power piston will generally tend to drift into the working space.

The leakage factors (FDBLK and FLEAK) are used to control the displacer and piston leakages. They are used whenever the centering ports are closed. Several leak paths exist for both the displacer and piston. The free-piston code currently simulates the major leak paths. For the displacer, leakage occurs between the displacer gas spring and the bounce space. The major leak path is the one between the centering port of the displacer bore to the centering port in the displacer rod. For the piston, leakage occurs between the compression space and the bounce space. The major leak path in this case is the one between the centering port in the piston to the centering port in the cylinder wall.

The dashpot load coefficient (CV2LD) is used to vary the piston stroke. Typically, CV2LD is varied until the code predicts the desired piston stroke.

Initially, all of the calibration parameters are set at their nominal values. Running the code with the nominal calibration parameters represents a code without engine-specific factors. The nominal values are

FMULT $=1.0$

RHCFAC $=1.0$

FHEXP $=1.0$

FHCOMP $=1.0$

CPTDO $=1.0 \times 0^{-3} 1 b_{m} / \mathrm{s} \sqrt{p s i}$

FDBLK $=1.0$

CPTPO $=1.0 \times 10^{-3} 1 \mathrm{~b}_{\mathrm{m}} / \mathrm{s} \sqrt{\mathrm{psi}}$

FLEAK $=1.0$

CV2LD $=2.25 \times 10^{-2} 1 b_{f}-s^{2} / i n$. (at engine design conditions)

The nominal value for the load coefficient CV2LD is calculated using the equation

CVILD $=\frac{3}{32 \pi} \frac{P_{C a^{A} p} \sin \theta}{\omega^{2} x_{p}{ }^{2}}$

This equation gives the value of the velocitysquared load coefficient required to produce a sinusoidal piston motion with frequency $\omega$ and amplitude $X_{p}$ when the compression space pressure wave is sinusoidal with amplitude $P_{c a}$ and phase $\theta$ relative to the piston motion.

\section{Constrained Mode Calibration}

The experimental case selected for the initial step of the code calibration was run 1010 of the Lewis RE-1000 sensitivity test data. ${ }^{3}$ This experimental data point was taken with the engine operating at its design conditions. The operating conditions were as follows: piston stroke, $2.60 \mathrm{~cm}$; heater-tube outside-wall temperature, $600{ }^{8} \mathrm{C}$; cooling-water inlet temperature, $25{ }^{8} \mathrm{C}$; mean working-space pressure, 7.0 MPa (1015 psi); working fluid, helium. The calibration process began with the model operating in the constrained mode. The constrained mode was used to calibrate the code for the RE-1000's thermodynamics. In this mode of operation the motions of the piston and displacer are specified as Fourier series. Only the fundamental terms (first harmonics) of the measured motions were used as inputs. The amplitudes of the higher order terms were found to be relatively small compared with the amplitudes of the fundamental terms which indicates that the piston and displacer motions were almost sinusoidal. As a result, the difference between the code predictions using only the fundamental terms of the Fourier series and the code predictions using the first three terms of the Fourier series is insignificant (Figs. 5 and 6). This was found to be true for the RE-1000 with the dashpot load but may not be true for a different type of load (i.e., a hydraulic pump load). The inputs for the 
piston and displacer in the form of Fourier series were as follows (amplitudes are in centimeters):

$x_{p}=-0.003+1.300 \sin \omega t$

$x_{d}=0.470+1.170 \sin \left(\omega t+57.5^{\circ}\right)$

The factors FHCOMP, FHEXP, FMULT, and RHCFAC were available for adjustment in the constrained mode. These parameters were chosen since they all directly affect the engine's thermodynamics. FHCOMP and FHEXP were adjusted to obtain the correct compression space pressure wave amplitude and phase angle. FMULT was adjusted until good agreement was reached between predicted and measured pressure drop amplitudes across the cooler, regenerator, and displacer. The experimental pressure drop amplitude measurements were fairly accurate as indicated by Schreiber et al. 3 A great amount of work was done on the measurement techniques to insure accuracy. RHCFAC was left at its nominal value since the predicted indicated efficiency was already within the experimental error band. Once good agreement was reached between measured and predicted pressure drops, pressure amplitudes, and phase angles, the estimated cylinder wall temperatures were varied until good agreement was reached between the measured and predicted expansion and compression space gas temperatures.

The displacer spring constant and damping factor required to achieve the correct displacer motion were then calculated by the code from a phasor diagram (Fig. 7) for use in the unconstrained mode of operation. The vectors $\overrightarrow{P_{C} A_{d r}}$ and $\overrightarrow{\left(P_{C}-P_{E}\right) A_{d}}$ were calculated by Fourier analysis of the simulated pressure drop and compression space pressure. The vector $\overline{M_{d} x_{d}}$ was obtained from the differentiation of the displacer amplitude vector $\overrightarrow{X_{d}}$. The gas spring force required to produce the simulated displacer dynamics can be calculated from the following vector operation:

$\overrightarrow{F_{S}}=\overrightarrow{M_{d} \ddot{x}_{d}}-\left[\overrightarrow{P_{C} A_{d r}}+\left(\overrightarrow{\left.P_{C}-P_{F}\right) A_{d}}\right]\right.$

The vector $\overrightarrow{F_{S}}$ can then be resolved into the damping and spring components so that

$\overrightarrow{F_{s}}=\overrightarrow{C_{d s} \overrightarrow{x_{d}}}+\overrightarrow{K_{d s^{x}}}$

The value of the displacer spring constant as calculated by the code was checked against the adiabatic spring constant as calculated using the equation

$K_{d s a l}=\frac{P_{D}\left(A_{d r}\right)^{2}}{V_{d o}}$

This was done to insure that the spring constants calculated by the code were realistic in that they cannot be greater than their adiabatic limits.

Semiconstrained Mode Calibration

In this mode of operation, the motion of the piston is specified (constrained) while the displacer motion is calculated (unconstrained). This mode of operation aids in the calibration of the displacer dynamics when a control volume representation is used for the displacer gas spring model. But since a spring constant/damping factor representation was used, the semiconstrained mode of operation was not necessary for the calibration process documented in this report.

\section{Unconstrained Mode Calibration}

In the unconstrained mode of operation, the motions of the piston and displacer are calculated. CV2LD, FLEAK, and CPTP0 are available for adjusting. These parameters are primarily used to adjust the piston dynamics. The parameters FDBLK and CPTDO, which are used to adjust the displacer dynamics, were left equal to their nominal values since the spring constant/damping factor representation was being used for the displacer gas spring. CV2LD was adjusted until the predicted and measured piston strokes matched.

If the predicted and measured displacer strokes did not match, the factor FMULT (which was previously adjusted in the constrained calibration) had to be readjusted. Changing the value of FMULT changes the constrained calibration which means that the calibration process must be repeated.

Several iterations between constrained and unconstrained modes were required to complete the calibration for the design point, run 1010 . Table 1 compares the experimental data for the design point to the final predicted performance parameters for both the constrained and unconstrained simulations. A flow chart summarizing the calibration process is shown in Fig. 8 .

After the calibration was completed for the design point, predictions were made for off-design conditions and were compared with experimental data. Each off-design point had only one of the operating conditions varied from the design conditions. The experimental runs used for the offdesign conditions were as follows: (1) run 1006 (piston stroke, $1.80 \mathrm{~cm}$ ), (2) run 1012 (piston stroke, $3.00 \mathrm{~cm}$ ), (3) run 1030 (heater-tube outside-wall temperature, $450^{\circ} \mathrm{C}$ ), (4) run 1079 (mean working-space pressure, $4.0 \mathrm{MPa}$ ), and (5) run 1200 (cooling-water inlet temperature, $55^{\circ} \mathrm{C}$ ). These runs represented the extremes of the operating conditions. The calibration parameters were then adjusted to improve the agreement over the entire range of operating conditions. The major calibration effort concerned the reference case or design point. Minor adjustments were then made for the five off-design points to improve the overall agreement.

\section{Results and Discussion}

\section{Final Set of Calibration Factors}

The free-piston Stirling engine code was calibrated against a matrix of six experimental data points which represented the design point and off design points (extremes) of engine operating conditions. The set of calibration parameters which resulted in the best agreement between the predicted and measured data over the entire matrix of calibration runs was:

FMULT $=1.2$

$\star$ RHCFAC $=1.0$

FHEXP $=230.0$

FHCOMP $=50.0$

${ } \mathrm{CPTDO}=1.0 \times 10^{-3} 1 \mathrm{bm} / \mathrm{s} \sqrt{\mathrm{psi}}$ 
$\star F D B L K=1.0$

*CPTPO $=1.0 \times 10^{-3} 1 \mathrm{~b}_{\mathrm{m}} / \mathrm{s} \sqrt{\mathrm{psi}}$

FLEAK $=1.2$

CV2LD $=2.24 \times 10^{-2} \mathrm{lbf}_{\mathrm{f}} \mathrm{s}^{2} / \mathrm{in}$. (Value of CV2LD for run 1010 only)

where * indicates factors and coefficients still at their nominal values.

Most of the final calibration factors and coefficients were very close to the nominal ones. Although the final values of FHEXP and FHCOMP appear quite large, when they are compared with the values required to isothermalize the cylinder, the final values are relatively low. Figure 9 shows the expansion and compression space gas temperature ranges plotted as a function of the calibration factors FHEXP and FHCOMP. For non isothermal cylinders, there is a large cyclic gas temperature variation in the expansion and compression spaces. The gas temperature range indicated in Fig. 9 is equal to twice the amplitude of this cyclic variation. Therefore, a zero range indicates nearly isotherma1 conditions. Both FHEXP and FHCOMP were varied simultaneously over a wide range of values. The value of FHEXP required to isothermalize the expansion space was found to be $\sim 20000$ while the value of FHCOMP required to isothermalize the compression space was found to be $\sim 100000$. One possible reason for the big difference between these two values is that in the RE- 1000 the average sur$f$ ace area for heat transfer in the expansion space and the displacer appendix gap is almost four times larger than the average surface area for heat transfer in the compression space. It should be noted that for the calibration values of FHEXP and FHCOMP selected, the average heat-transfer coefficient predicted in the expansion and compression space at engine design conditions was 7.6 and $6.8 \mathrm{~W} / \mathrm{cm}^{2}-{ }^{\circ} \mathrm{C}$, respectively. For the isothermal. case, these values would be 527 and $1300 \mathrm{~W} / \mathrm{cm}^{2}-{ }^{\circ} \mathrm{C}$, respectively.

\section{Additional Runs}

Four additional data points, runs 1017, 1024, 1070 , and 1121, were used as intermediate points for the final comparisons. 3 Runs 1017 and 1024 were for mean heater-tube temperatures of 550 and $500{ }^{\circ} \mathrm{C}$ with the design operating conditions of piston stroke of $2.60 \mathrm{~cm}$, cooling-water inlet temperature of $25^{\circ} \mathrm{C}$, and mean working-space pressl'.e of $7.0 \mathrm{MPa}$. Experimental run 1070 was for an intermediate mean pressure of $5.5 \mathrm{MPa}$ while run 1121 was for an intermediate cooling-water inlet temperature of $40^{\circ} \mathrm{C}$ with the other operating conditions at their design values.

\section{Comparison of Engine Dynamics and Thermodynamics}

The final set of calibration parameters was used to make comparisons of predicted piston and displacer strokes, phase angles, and frequency; gas pressure amplitude; and gas temperatures in the expansion and compression spaces against measured data. Comparisons of predicted and measured data are shown as a function of piston stroke in Figs. 10 through 16. The piston stroke of the engine was adjusted by varying the engine load; the piston stroke in the simulation was adjusted by varying the dashpot load coefficient (CV2LD). The comparisons are shown for a range of piston strokes with the heater-tube temperature, cooling-water inlet temperature, and mean working space pressure set at their design values. Error bands have been placed on the experimental data. The error bands indicate the measurement error associated with each reading of data. ${ }^{3}$ The ultimate goal of the calibration process was for the code predictions to fall within the error bands.

Figure 10 shows the predictions of the piston and displacer strokes to be in good agreement over most of the tested load range. Figure 11 shows the predicted piston-displacer phase angle within the experimental error band $\left(+1^{\circ}\right)$ over the entire load range. This good agreement can be attributed to the use of the spring constant/damping factor representation of the displacer gas spring. It should be noted that the actual piston-displacer phase angle at the engine design conditions was higher than the design phase angle of $45^{\circ}$. This difference was probably due to a slightly higher displacer damping force than assumed during the design process. A phasor diagram of the forces acting on the displacer was helpful in reaching this conclusion (Fig. 7). The magnitude of the displacer damping force is difficult to predict. The phasor diagram shows that the displacer damping force has a direct affect on the pistondisplacer phase angle. Figure 12 shows the predicted piston-pressure phase angle falls within the experimental data's error band $\left( \pm 1^{\circ}\right)$ over most of the tested load range. The good agreement between the predicted and measured phase angle is a result of increased cylinder heat transfer by means of the calibration factors FHEXP and FHCOMP. These two factors also had a positive effect on the compression-space pressure amplitude. The compression-space pressure amplitude has always been overpredicted in the past. Increasing the cylinder heat transfer brought the predicted amplitude within the error band $( \pm 20 \mathrm{kPa})$ of the experimental data. Figure 13 shows that the predicted engine frequency increases slightly with stroke while the measured frequency is almost constant. Figures 14 and 15 show the expansion and compression space gas temperatures compared with the experimental data. The good agreement shown for the expansion space can be attributed to the better estimates of the cylinder-wall temperatures. The good agreement shown for the compression space is a result of the new cooler model and the better estimates of the cylinder-wall temperatures. Figure 16 shows the predicted compression-space pressure amplitude to fall within the experimental data's error band $( \pm 20 \mathrm{kPa})$ over most of the tested load range.

\section{Comparison of Power and Efficiency}

Figures 17 to 24 show comparisons for power and efficiency between the engine test data and the code predictions. These comparisons were made for varying piston stroke, mean work ing-space pressure, mean heater-tube temperature, and coolingwater inlet temperature. Fiqure 17 shows the predicted power to fall within the experimental error $b$ and $( \pm 40 \mathrm{~W})$ over most of the range of piston strokes. Figure 18 shows the predicted efficiency to fall outside the error band $( \pm 1.3$ percent) at the lower piston strokes. The experimental data show a significant drop in the engine efficiency at the high piston stroke. One possible reason for this might be due to a higher heat-transfer loss out of the expansion space at the larger strokes. As the piston stroke is increased, the 
displacer stroke is also increased. This allows the expansion-space gas to come into contact with a cooler portion of the cylinder wall. The model does not simulate the drop in efficiency because the expansion-space wall temperature is assumed to be constant over its entire length. Comparisons of measured and predicted power and efficiency are shown as a function of mean working-space pressure in Figs. 19 and 20. The comparisons are shown for a range of mean pressures with the piston stroke, heater-tube outside-wall temperature, and coolingwater inlet temperature set at their design values. Figure 19 shows the predicted power to be slightly above the experimental data over most of the pressure range tested. Figure 20 shows the predicted efficiency to fall within the experimental error band $( \pm 1.3$ percent) over the entire range of pressures tested although the shapes of the curves are significantly different.

Comparisons of measured and predicted power and efficiency are shown as a function of mean heater-tube outside-wall temperature in Figs. 21 and 22. The mean heater-tube outside-wall temperature was experimentally measured by taking the average of twelve heater-tube temperatures; six of which were measured at the quarter-length point at the expansion space end of the heater tube, while the other six were measured at the quarter-length point of the heater tube near the regenerator end of the tube. For these comparisons the piston stroke, mean working-space pressure, and coolingwater inlet temperature remain at their design values. Figure 21 shows the predicted power to fall within the experimental error band ( $\pm 40 \mathrm{~W})$ over the entire range of heater-tube temperatures. Figure 22 shows the predicted efficiency to fall below the experimental data over most of the range of heater tube temperatures although the shapes of the curves are similar.

Comparisons of measured and predicted power and efficiency are shown as a function of coolingwater inlet temperature in Figs. 23 and 24 . For these comparisons the piston stroke, mean workingspace pressure, and mean heater-tube outside-wall temperature remain at their design values.

Figure 23 shows the predicted power to fall slightly above the experimental data over most of the range of cooling-water inlet temperatures. Figure 24 shows the predicted efficiency to fall within the experimental error band $( \pm 1.3$ percent) over the entire range of cooling-water inlet temperatures.

\section{Concluding Remarks}

Many modifications have been made to the NASA Lewis free-piston Stirling engine code. The recent improvements have had a positive affect on the code predictions. Further development of the free-piston code should bring the predicted and measured data into even better agreement. The ultimate goal is to have a code that does not require any engine-specific calibration parameters. This would allow the code to be used to model any free-piston Stirling engine without having to go through the calibration process. More importantly the code could be used in conjunction with design codes to confidently design future free-piston Stirling engines. The results of the work done and documented in this report indicate several areas that require improvement:
1. New heat-transfer correlations are required for the expansion and compression spaces. This heat transfer is not well understood and the effect appears to be significant.

2. The friction-factor and heat-transfer correlations for the three Stirling cycle heat exchangers assume steady-state conditions. The effects of oscillating flow and pressure level need to be better understood.

3 . The leakage and centering port flow calculations should be verified. Currently, no experimental data of this type exist for the verification.

4. More information is required on gas springs in terms of irreversible heat-transfer (hysteresis) loss.

Current plans are to continue the validation of the free-piston model for the RE-1000 engine with a hydraulic output load. A subroutine for simulating the hydraulic load has been added to the free-piston code. The hydraulic output subroutine needs further development. The RE-1000 free-piston Stirling engine hydraulic output system is currently being debugged and readied for testing at NASA Lewis.

Other code validation work is also proceeding at NASA Lewis with the Stirling engine kinematic code. The predictions of this code with no engine-specific calibration parameters are being compared to test data from a variety of Stirling engines. RE-1000 test data and predictions of the free-piston code as described in this report but without the engine-specific calibration parameters will be input to this validation effort.

\section{REFERENCES}

1. Tew, R., Jefferies, K., and Miao, D., "A Stirling Engine Computer Model for Performance Calculations," NASA TM-78884, 1978.

2. Giansante, J.E., "A Free Piston Stirling Engine Performance Code," Report 81TR17, Mechanical Technology Inc., Latham, NY, Nov. 1980.

3. Schreiber, J., Geng, S.M., Lorenz, G.V., "RE-1000 Free Piston Stirling Engine Sensitivity Test Results," NASA TM- 88846.

4. Tew, R.C., "Comparison of Free-Piston Stirling Engine Model Predictions with RE1000 Engine Test Data," Advanced Energy Systems - Their Role in Our Future, Vol. 3, American Nuclear Society, La Grange'Park, IL, 1984 , pp. 2073-2085. (A1so, NASA TM-83650).

5. Kays, W.M., London, A.L., Compact Heat Exchangers, Second ed. McGraw-Hi11, New York, 1964.

6. Holman, J.P., Heat Transfer, Fifth ed., McGraw-Hil1, New York, 1981.

7. Urieli, I., Berchowitz, D.M., Stirling Cycle Engine Analysis, Adam Hilger Ltd., 1984.

8. Ernst, W., Piller, S., Richey, A., Simetkosky, M. and Antonelli, M., "Automotive Stirling Engine Development Program," NASA CR-167907 MT I 82ASE278SA2, Oct. 1982, pp. 3-10. 
TABLE 1. Comparison of RE-1000 Predicated and Experimental Performance at Design Operating Conditions (Run 1010)

\begin{tabular}{|c|c|c|c|c|c|c|c|c|c|}
\hline \multirow{2}{*}{$\begin{array}{l}\text { Run } \\
\text { description }\end{array}$} & \multirow{2}{*}{$\begin{array}{c}\text { Frequency, } \\
\mathrm{Hz}\end{array}$} & \multirow{2}{*}{$\underset{k W}{\text { Heat in, }}$} & \multirow{2}{*}{$\begin{array}{l}\text { Heat out, } \\
\text { kW }\end{array}$} & \multicolumn{2}{|c|}{ Piston power } & \multirow{2}{*}{$\begin{array}{l}\text { Dash- } \\
\text { pot, } \\
\text { kW }\end{array}$} & \multirow{2}{*}{$\begin{array}{l}\text { Indicated } \\
\text { efficiency, } \\
\text { percent }\end{array}$} & \multirow{2}{*}{$\begin{array}{c}\text { Cycle } \\
\text { energy } \\
\text { balance } \\
\text { error }\end{array}$} & \multirow{2}{*}{$\begin{array}{c}\text { Piston } \\
\text { energy } \\
\text { balance } \\
\text { error }\end{array}$} \\
\hline & & & & $\begin{array}{c}\text { Indicated } \mathrm{PV}, \\
\mathrm{kW}\end{array}$ & $\begin{array}{c}\text { Phasor, } \\
\mathrm{kW}\end{array}$ & & & & \\
\hline $\begin{array}{l}\text { Experiment } \\
\text { Predicted: }\end{array}$ & 30.1 & 3.643 & 2.736 & 0.939 & 1.021 & 0.866 & 25.8 & 0.88 & -7.77 \\
\hline $\begin{array}{l}\text { Constrained } \\
\text { Unconstrained }\end{array}$ & $\begin{array}{l}30.1 \\
30.3\end{array}$ & $\begin{array}{l}3.921 \\
3.939\end{array}$ & $\begin{array}{l}3.036 \\
2.887\end{array}$ & $\begin{array}{l}.939 \\
.969 \\
\end{array}$ & $\begin{array}{l}.944 \\
.951\end{array}$ & $\begin{array}{l}.974 \\
.994\end{array}$ & $\begin{array}{l}23.9 \\
24.6\end{array}$ & $\begin{array}{r}1.38 \\
-2.12\end{array}$ & $\begin{array}{l}3.73 \\
2.58\end{array}$ \\
\hline
\end{tabular}

Experimental indicated power $=\frac{{ }_{C a}{ }^{A} V_{p} \cos \psi}{2}$

Predicted indicated power is determined by integrating $P-V$ diagram

Phasor diagram power $=\pi \omega P C a^{A} p_{p} \sin \theta$

Indicated efficiency $=\frac{\text { Indicated power }}{\text { Heat in }}$

Cycle energy balance error $=100\left[\frac{\text { Indicated power }+ \text { heat out }}{\text { Heat in }}-1\right]$

Power piston energy balance error $=100\left[\frac{\text { Dashpot power dissipation }}{\text { Indicated power }}-1\right]$ 


\section{ORIGINAL PAGE IS OF POOR QUALTY}

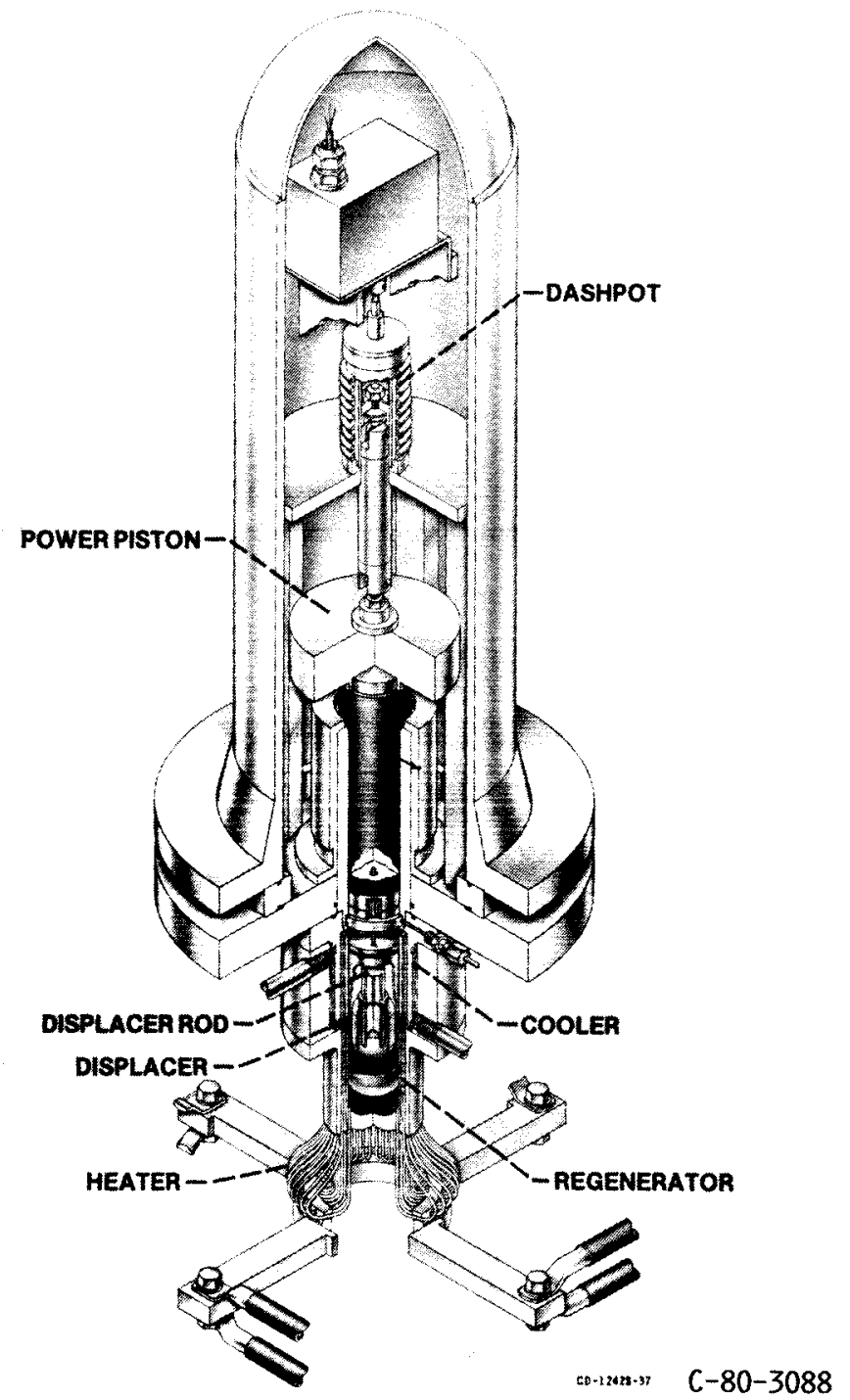

FIG. 1 CUTAWAY VIEW OF RE-1000 FREE-PISTON, STIRLING ENGINE. 


\section{ORIGINAL PAGE IS
OF POOR QUALTTY}

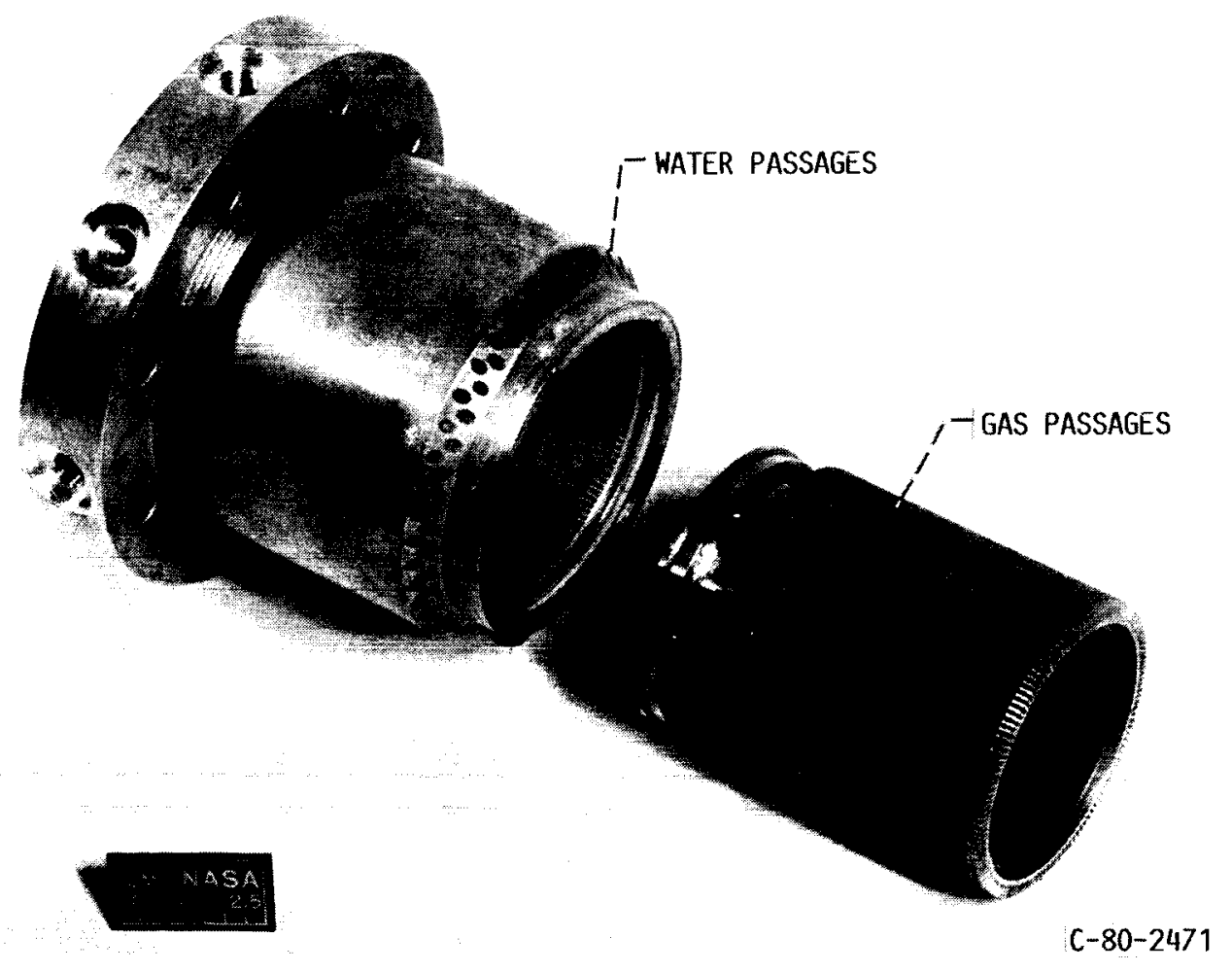

FIG. 2 RE-1000 COOLER. 


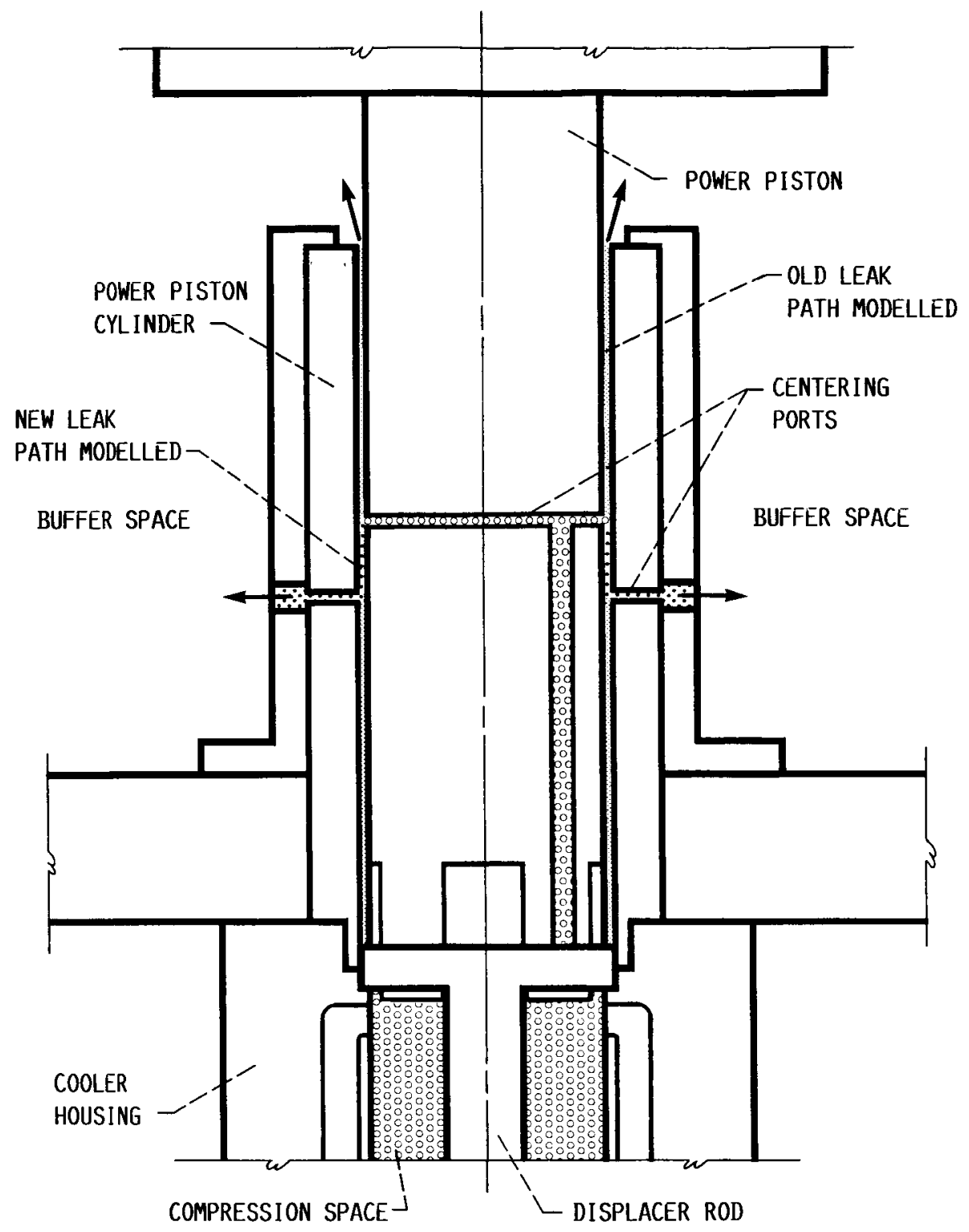

FIG. 3 POWER PISTON LEAK PATH OF RE-1000 ENGINE.

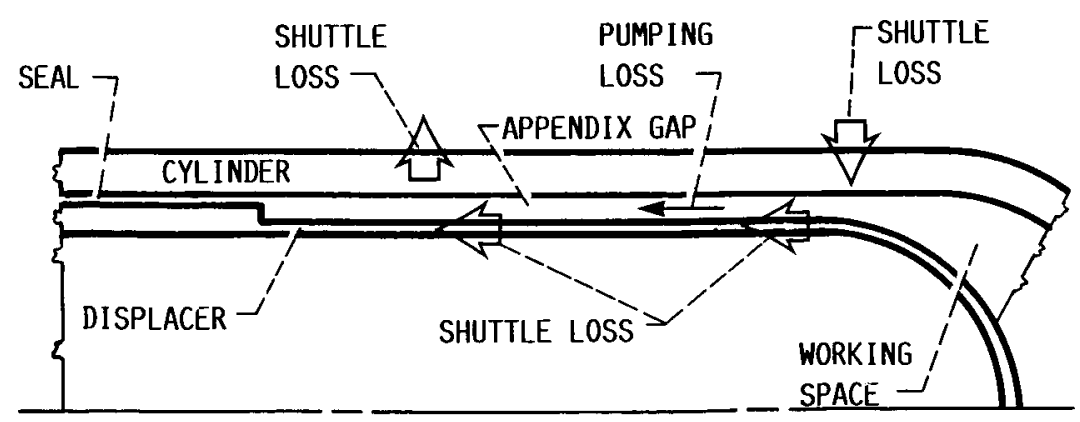

FIG. 4 DISPLACER APPENDIX GAP. 


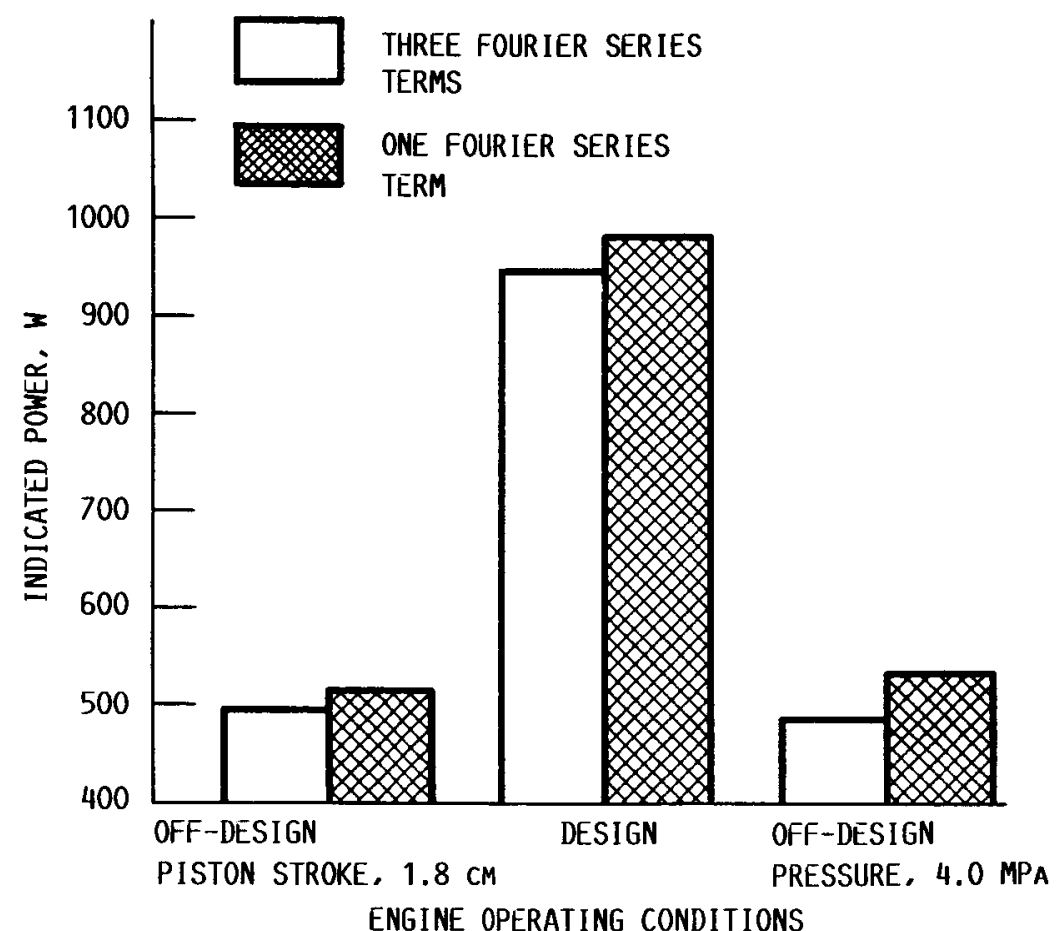

FIG. 5 COMPARISON OF INDICATED POWER PREDICTIONS USING ONE AND THREE FOURIER SERIES TERMS FOR PISTON AND DISPLACER.

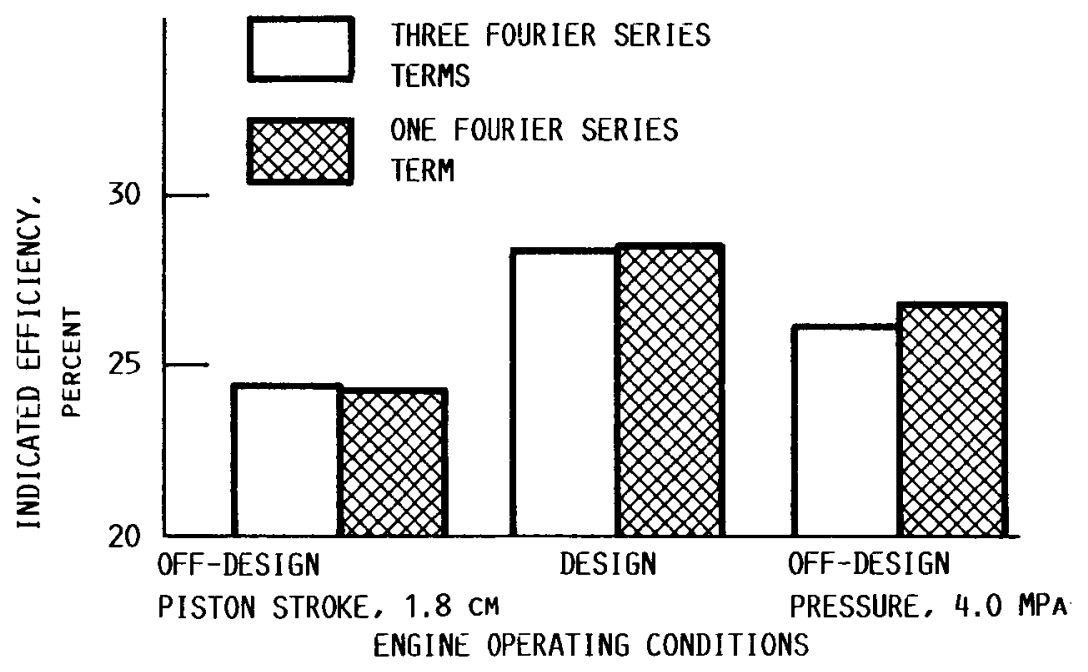

FIG. 6 COMPARISON OF INDICATED EFFICIENCY PREDICTIONS USING ONE AND THREE FOURIER SERIES TERMS FOR PISTON AND DISPLACER. 


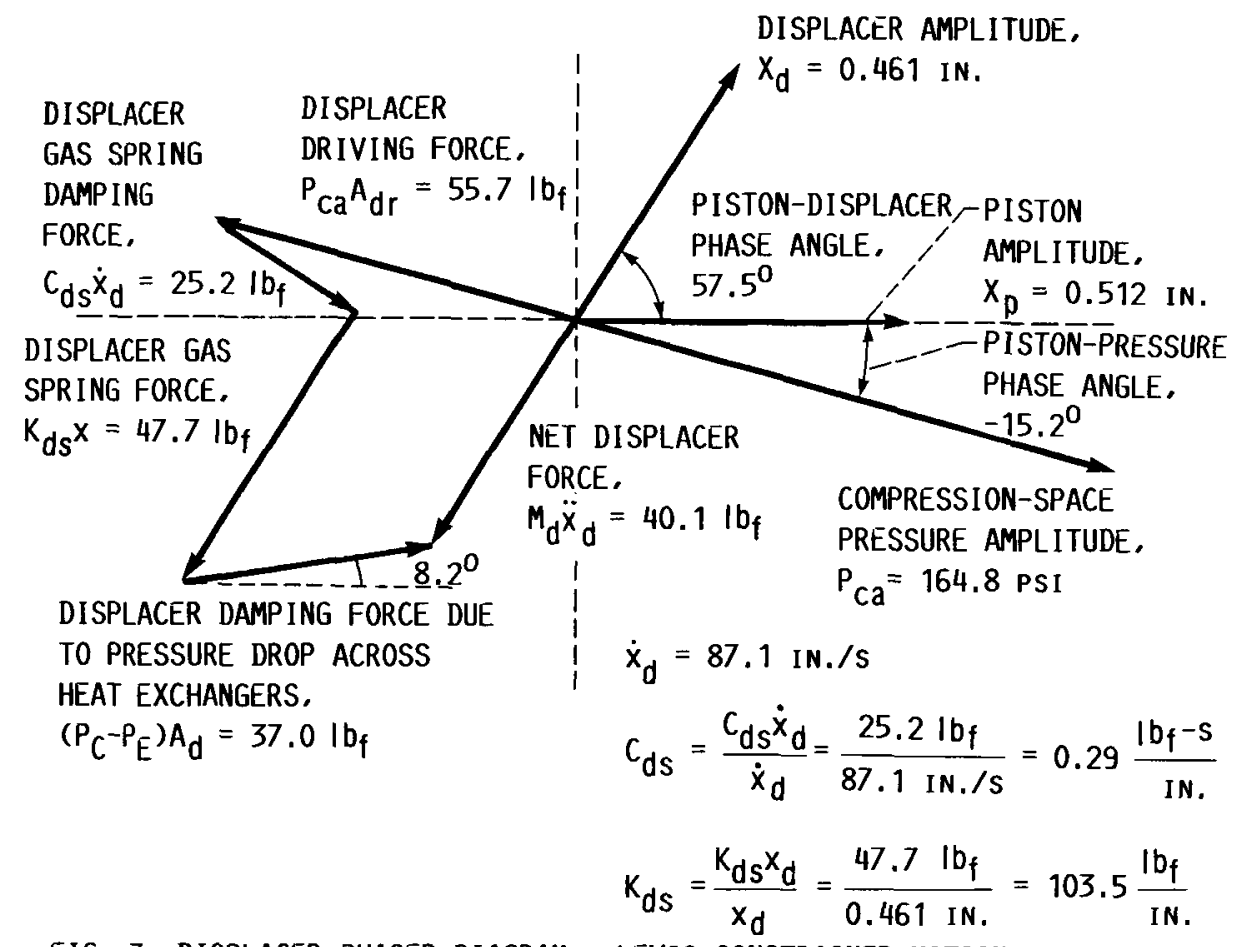

FIG. 7 DISPLACER PHASER DIAGRAM - LEWIS CONSTRAINED MOTION SIMULATION OF RUN 1010 (REFERENCE CASE). 


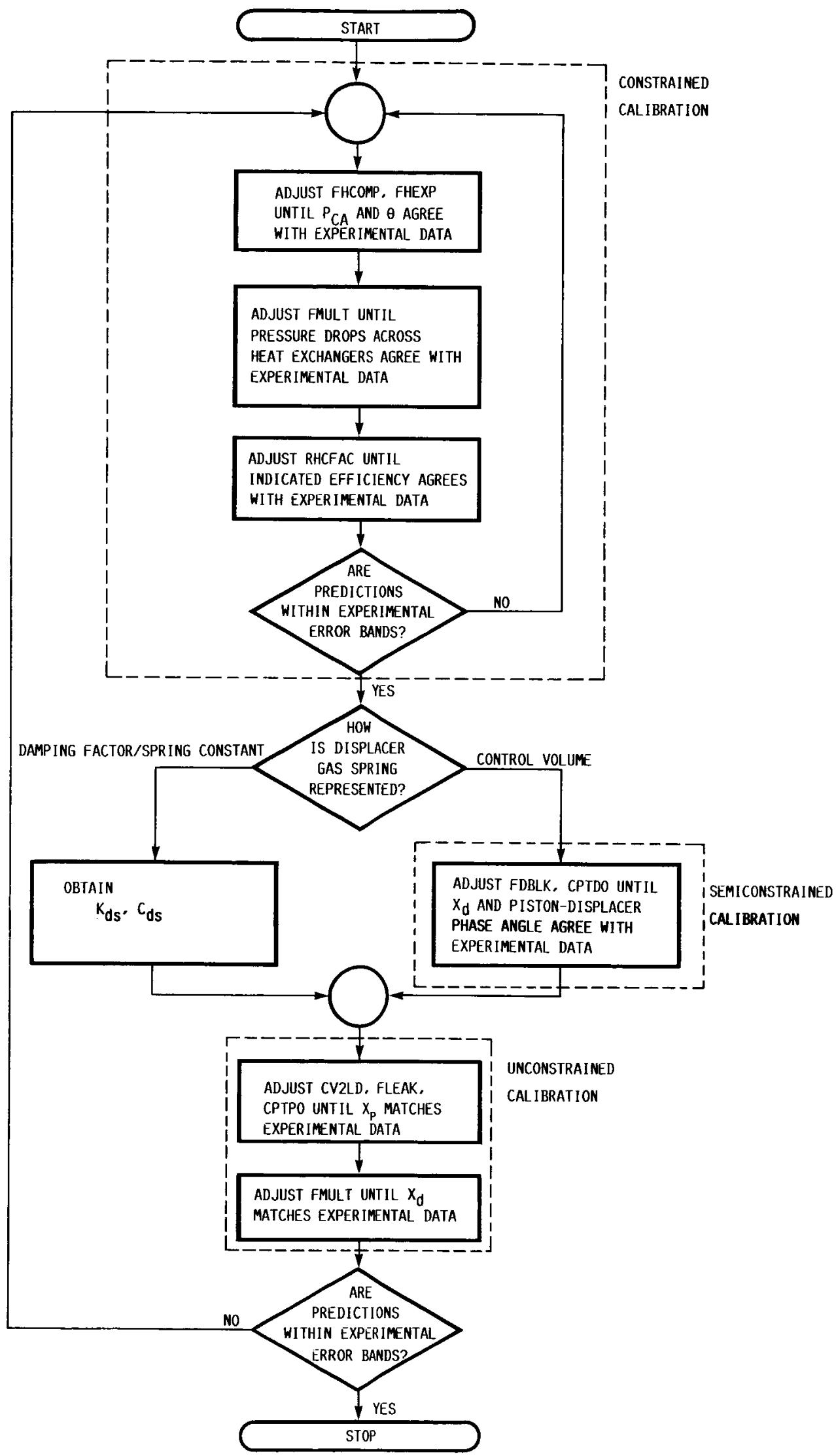

FIG. 8 FLOW CHART OF CALIBRATION PROCESS. 


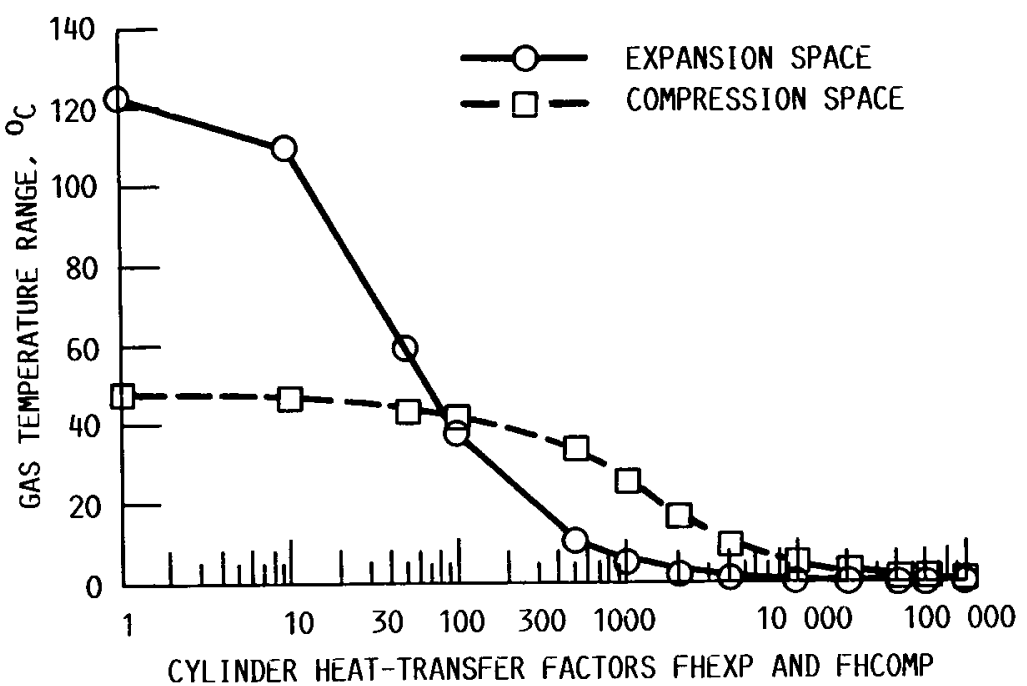

FIG. 9 EXPANSION AND COMPRESSION SPACE GAS TEMPERATURE RANGES VERSUS FHEXP AND FHCOMP (RANGE $=2 \mathrm{x}$ AMPLI ITUDE).

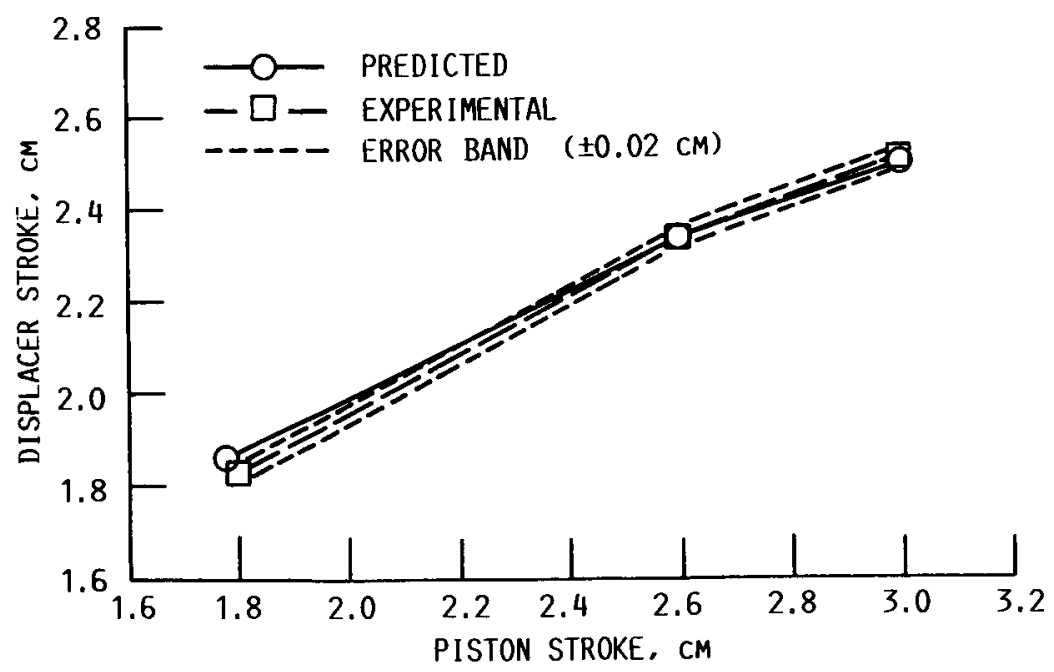

FIG. 10 DISPLACER STROKE VERSUS PISTON STROKE. 


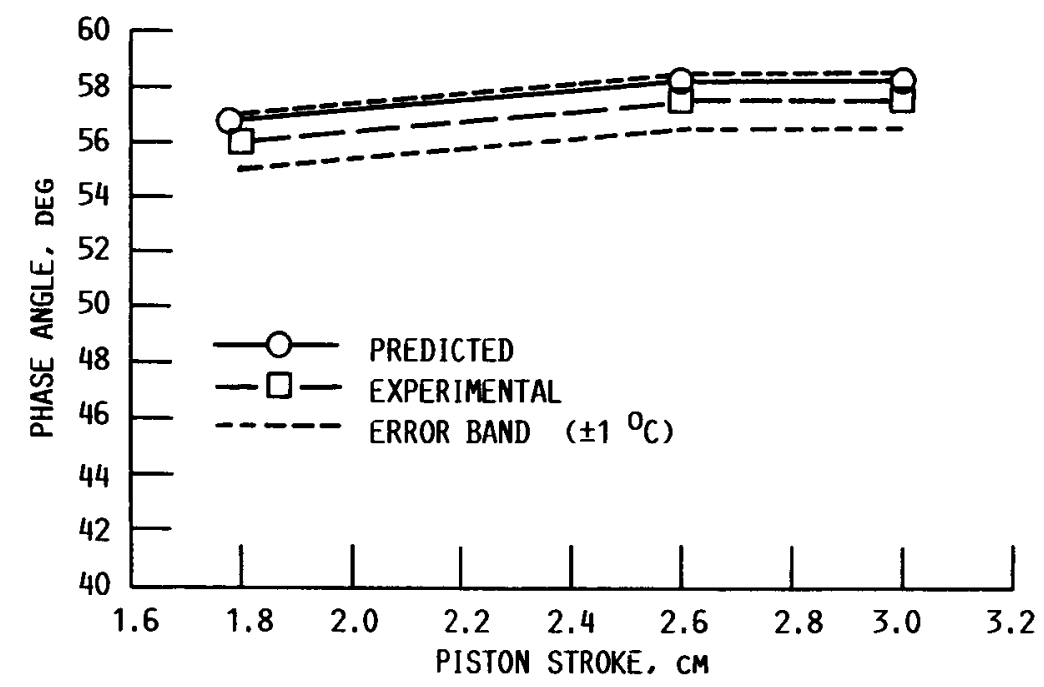

FIG. 11 PISTON-DISPLACER PHASE ANGLE VERSUS PISTON STROKE.

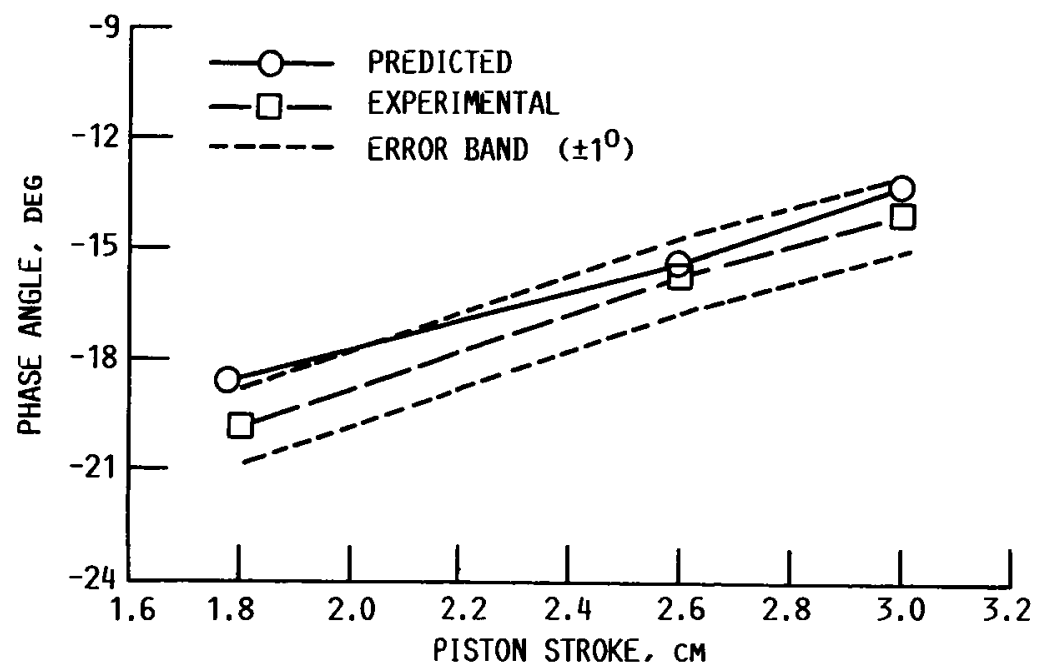

FIG. 12 PISTON-COMPRESSION SPACE PRESSURE PHASE ANGLE VERSUS PISTON STROKE. 


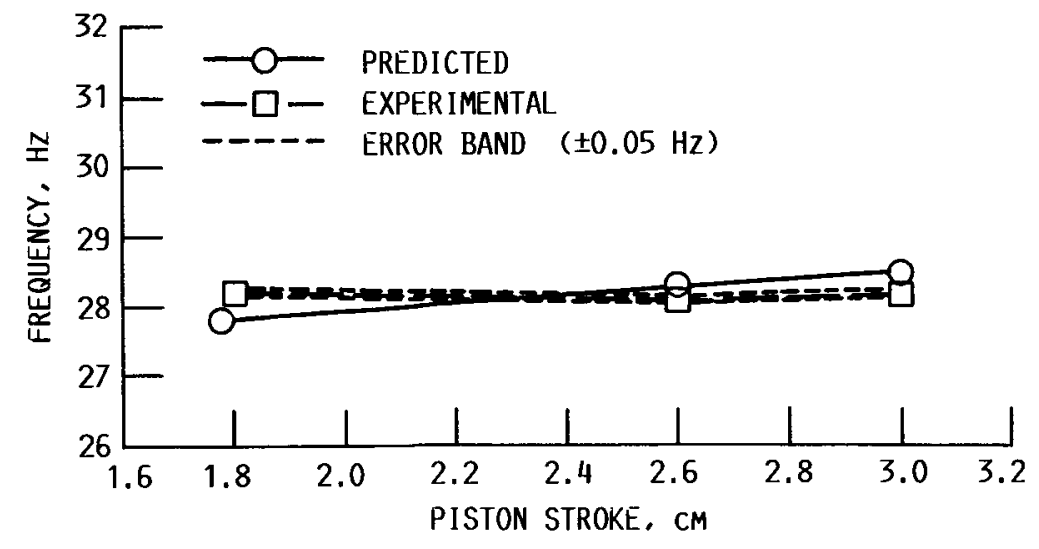

FIG. 13 ENGINE FREQUENCY VERSUS PISTON STROKE.

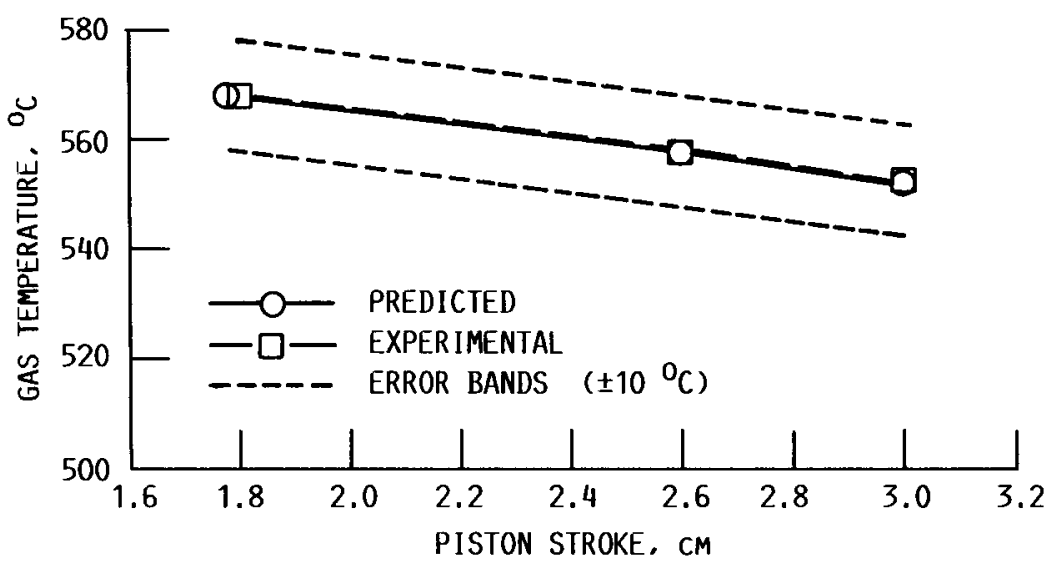

FIG. 14 EXPANSION-SPACE GAS TEMPERATURE VERSUS PISTON STROKE.

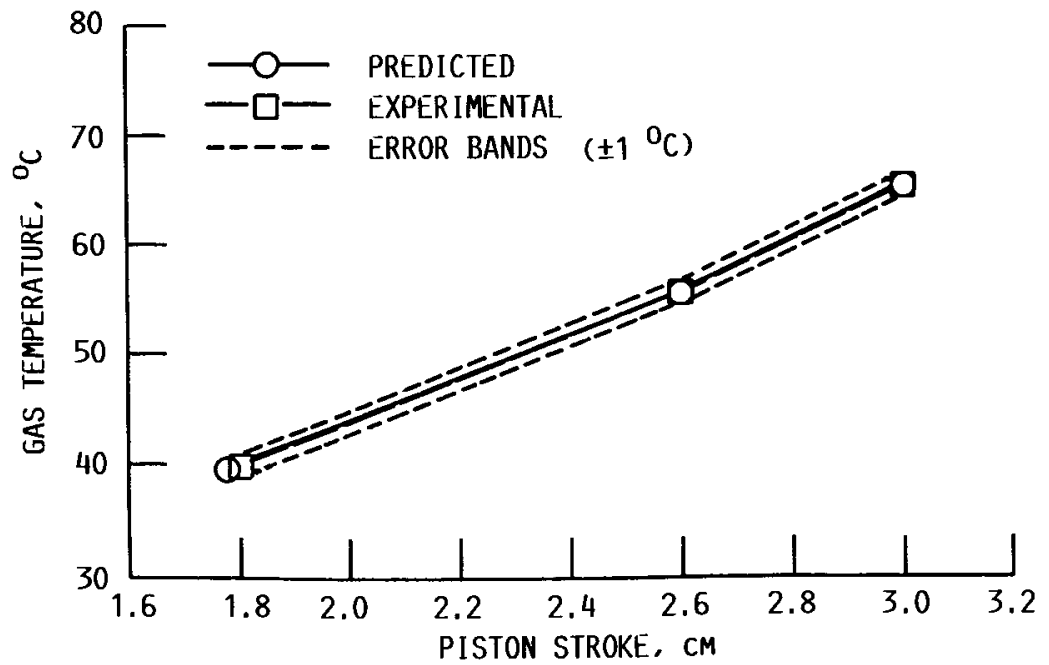

FIG. 15 COMPRESSION-SPACE GAS TEMPERATURE VERSUS PISTON STROKE. 


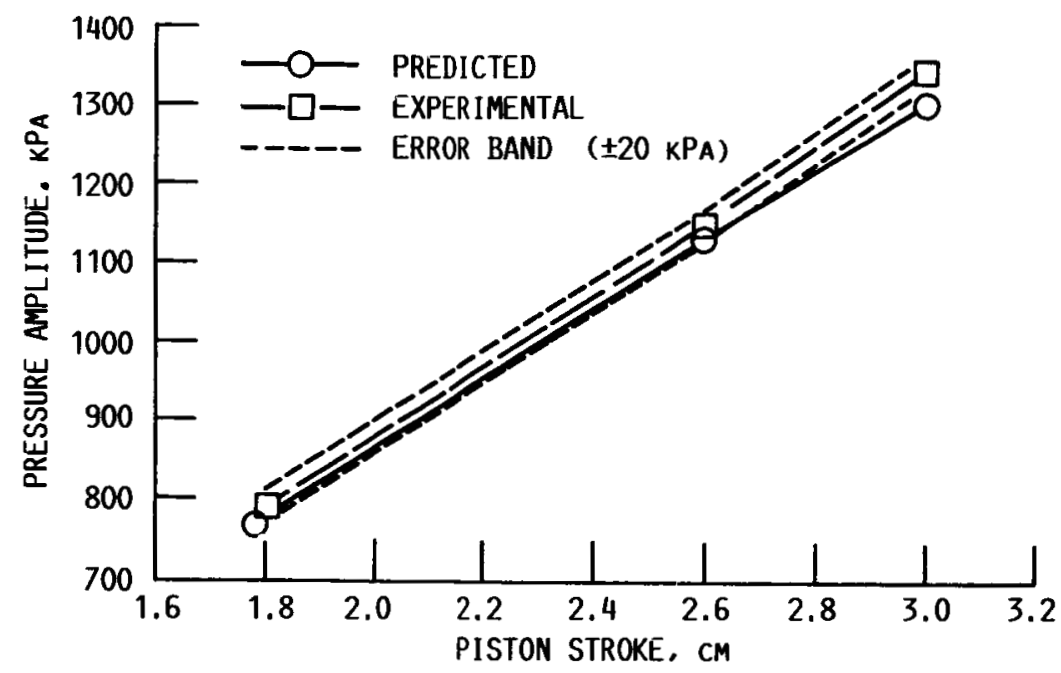

FIG. 16 COMPRESSION-SPACE PRESSURE AMPLITUDE VERSUS PISTON STROKE.

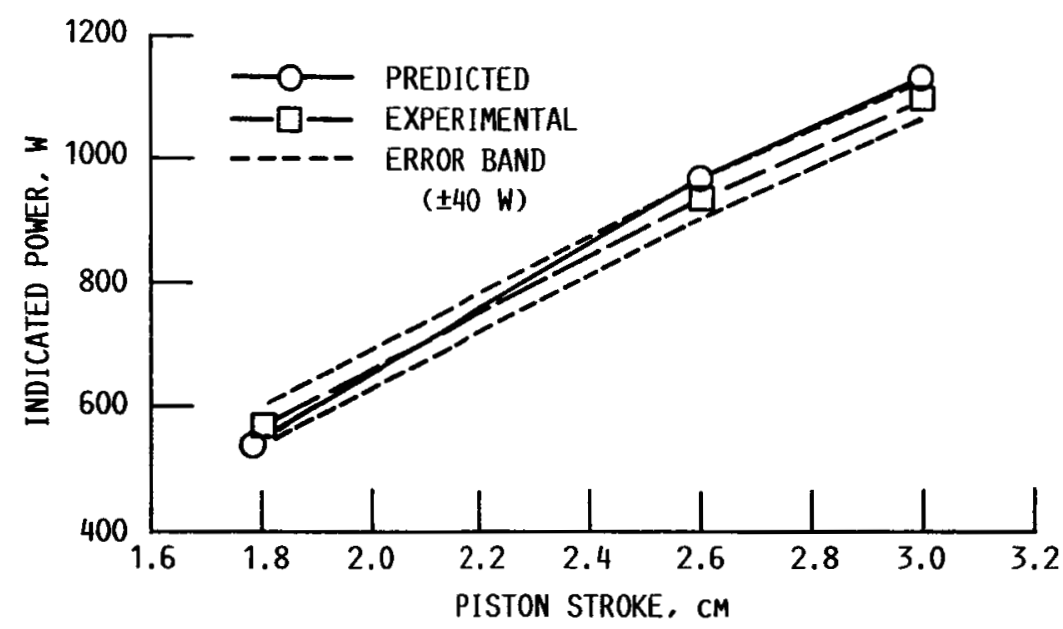

FIG. 17 INDICATED POWER VERSUS PISTON STROKE.

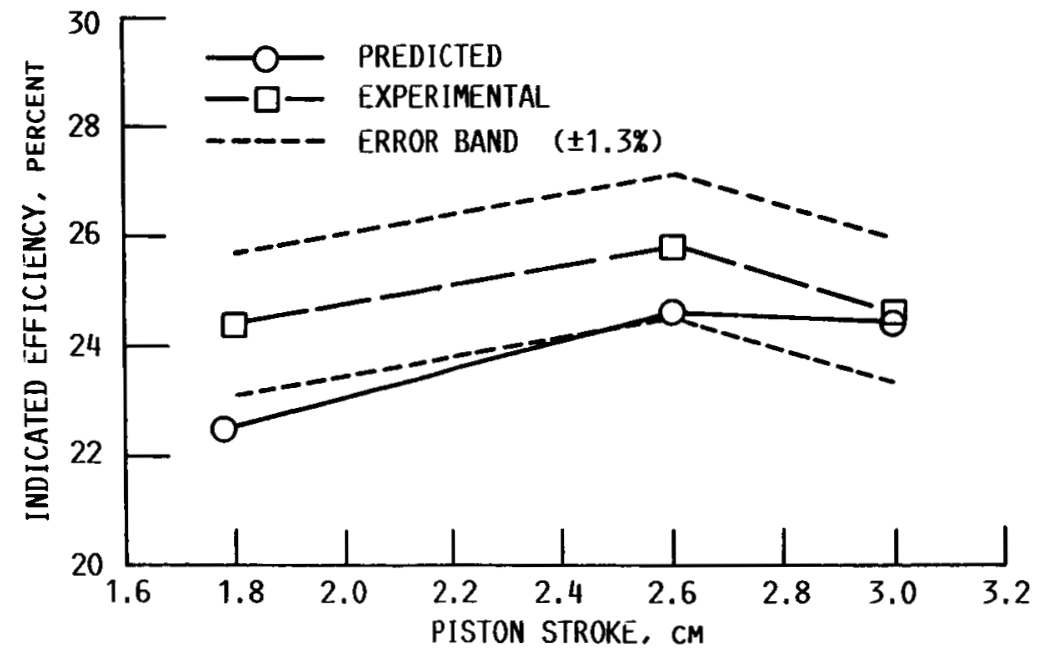

FIG. 18 INDICATED EFFICIENCY VERSUS PISTON STROKE. 


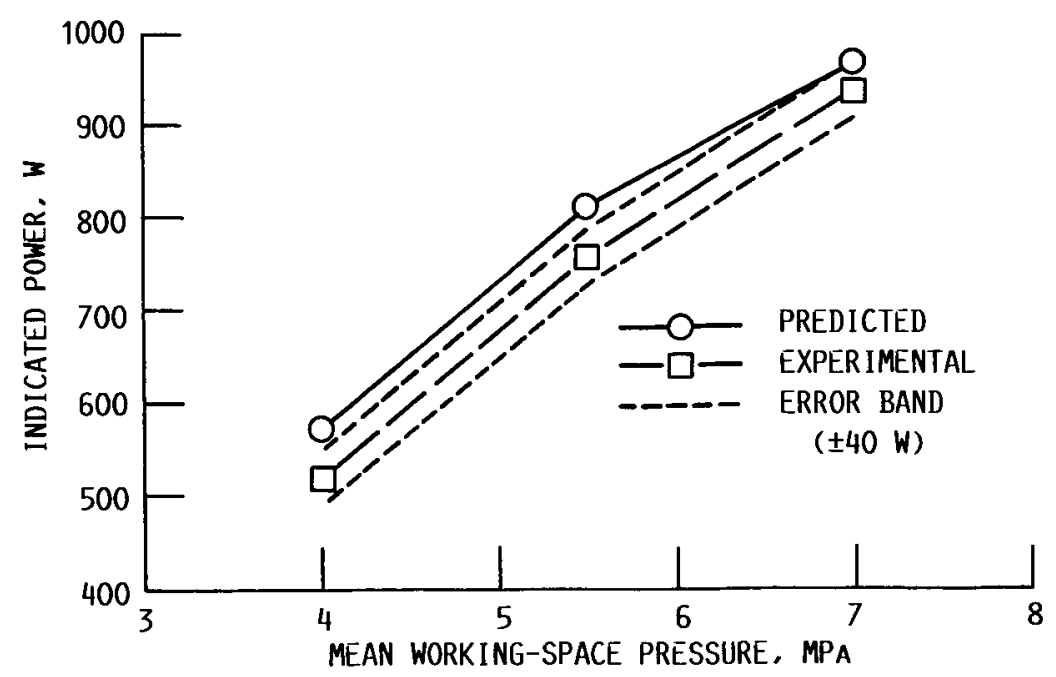

FIG. 19 INDICATED POWER VERSUS MEAN WORKING-SPACE PRESSURE.

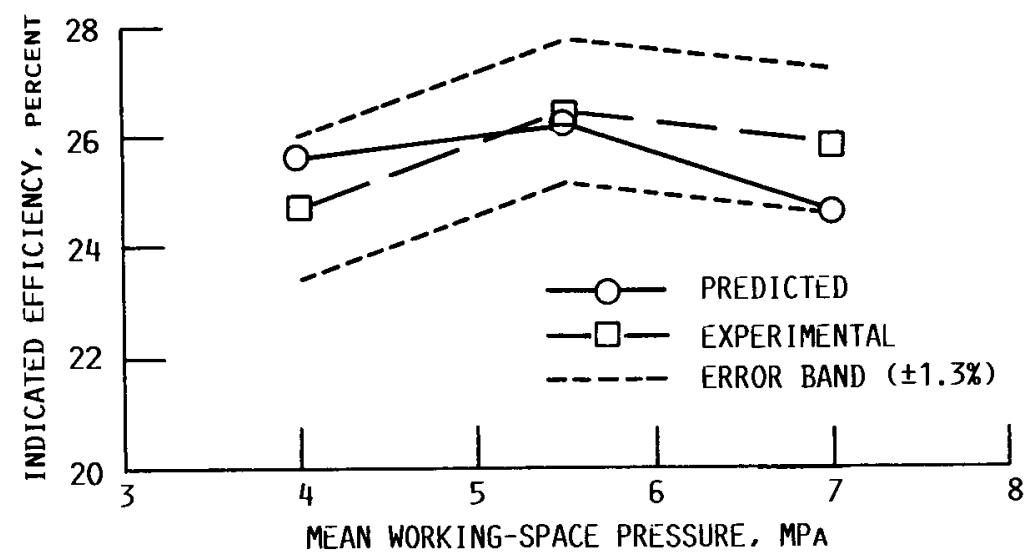

FIG, 20 INDICATED EFFICIENCY VERSUS MEAN WORKING-SPACE PRESSURE.

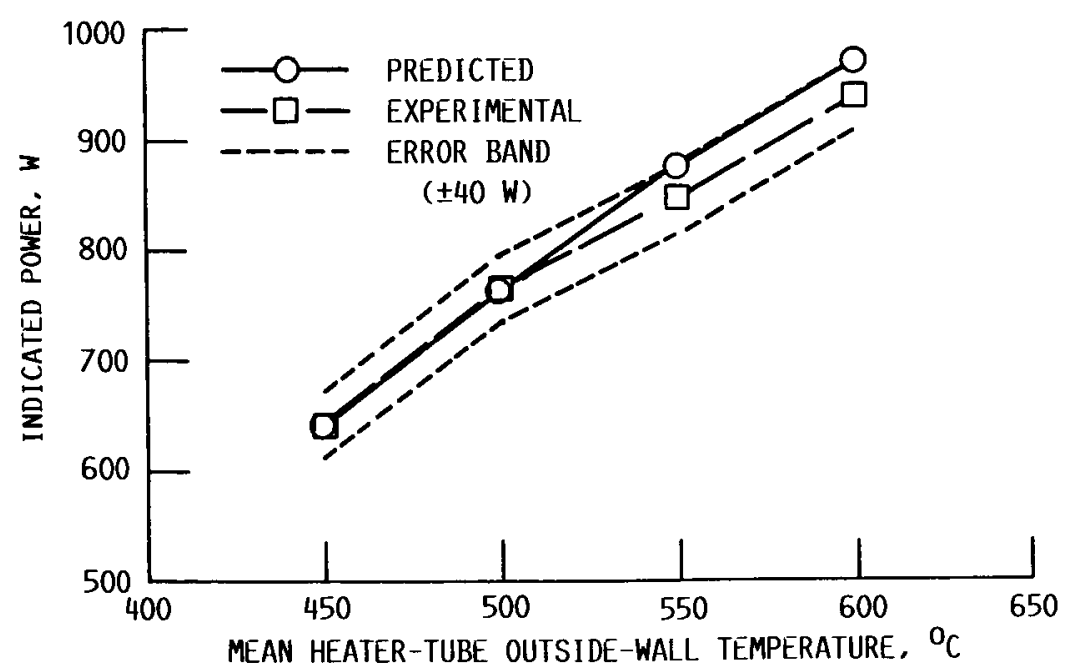

FIG. 21 INDICATED POWER VERSUS MEAN HEATER-TUBE TEMPERATURE. 


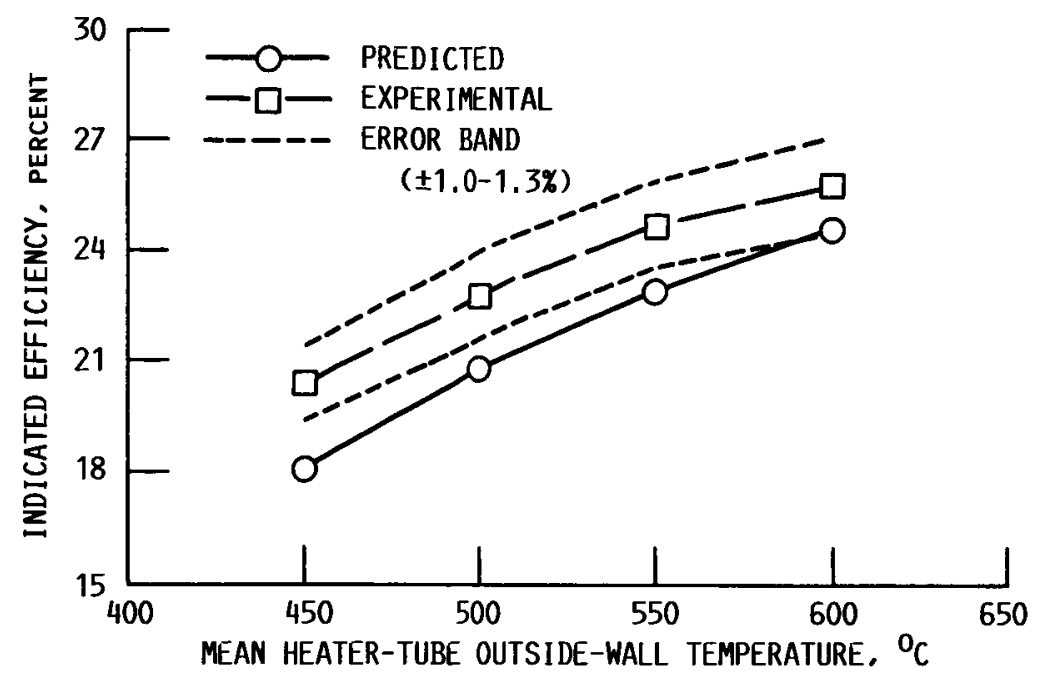

FIG. 22 INDICATED EFFICIENCY VERSUS MEAN HEATER-TUBE TEMPERATURE.

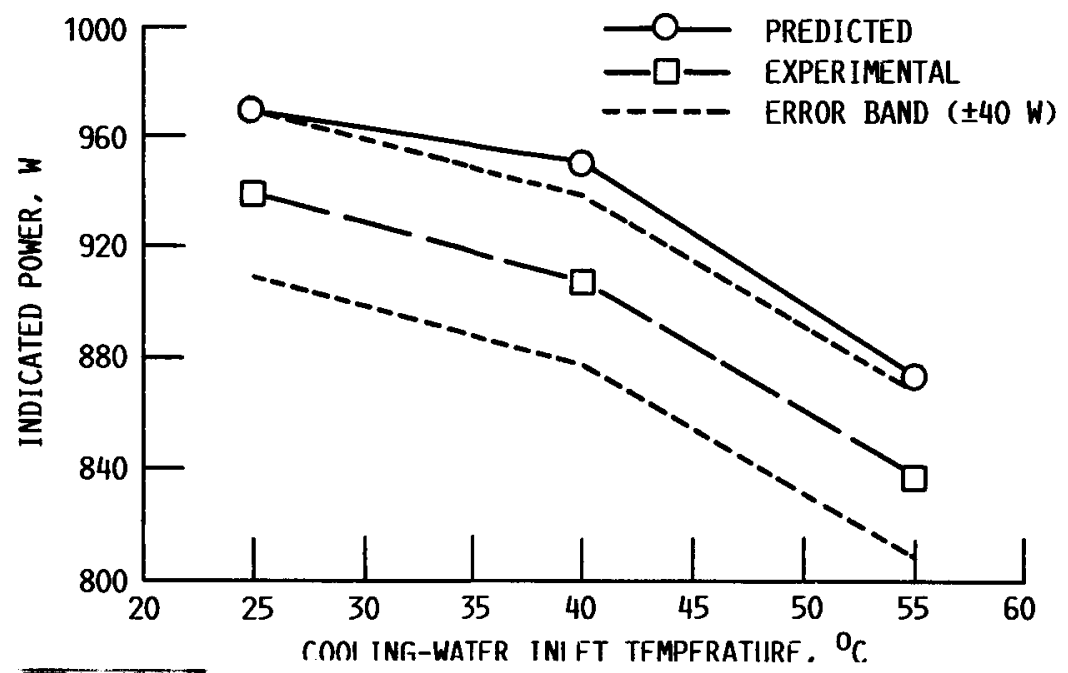

FIG. 23 INDICATED POWER VERSUS COOLING-WATER INLET TEMPERATURE.

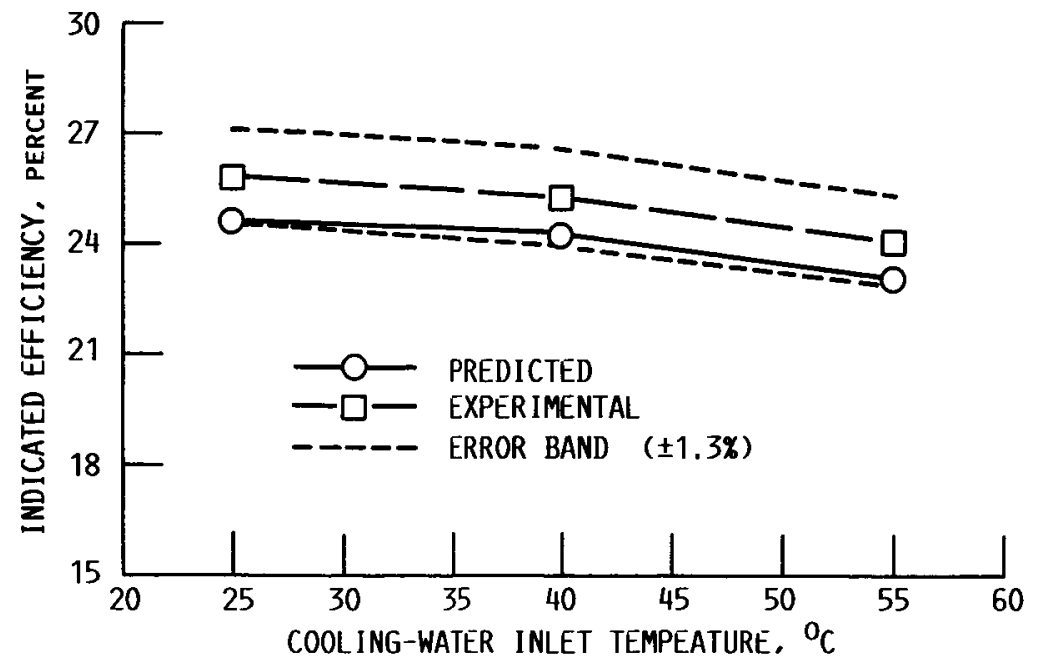

FIG. 24 INDICATED EFFICIENCY VERSUS COOLING-WATER INLET TEMPERATURE. 


\begin{tabular}{|c|c|c|c|}
\hline \multirow{3}{*}{\multicolumn{2}{|c|}{$\begin{array}{l}\text { 1. Report No. } \\
\text { NASA TM-89853 }\end{array}$}} & \multicolumn{2}{|c|}{ 3. Recipient's Catalog No. } \\
\hline & & \multicolumn{2}{|l|}{ 5. Report Date } \\
\hline & & \multicolumn{2}{|c|}{$\begin{array}{l}\text { 6. Performing Organization Code } \\
506-41-30\end{array}$} \\
\hline \multirow{2}{*}{\multicolumn{2}{|c|}{$\begin{array}{l}\text { 7. Author(s) } \\
\text { Steven M. Geng }\end{array}$}} & \multicolumn{2}{|c|}{$\begin{array}{l}\text { 8. Performing Organization Report No. } \\
\text { E-3520 }\end{array}$} \\
\hline & & \multicolumn{2}{|l|}{ 10. Work Unit No. } \\
\hline \multirow{3}{*}{\multicolumn{2}{|c|}{$\begin{array}{l}\text { 9. Performing Organization Name and Address } \\
\text { National Aeronautics and Space Administration } \\
\text { Lewis Research Center } \\
\text { Cleveland, Ohio } 44135\end{array}$}} & \multirow{2}{*}{\multicolumn{2}{|c|}{ 11. Contract or Grant No. }} \\
\hline & & & \\
\hline & & \multirow{2}{*}{\multicolumn{2}{|c|}{$\begin{array}{l}\text { 13. Type of Report and Period Covered } \\
\text { Technical Memorandum }\end{array}$}} \\
\hline \multirow{2}{*}{\multicolumn{2}{|c|}{$\begin{array}{l}\text { 12. Sponsoring Agency Name and Address } \\
\text { National Aeronautics and Space Administration } \\
\text { Washington, D.C. } 20546\end{array}$}} & & \\
\hline & & \multicolumn{2}{|c|}{ 14. Sponsoring Agency Code } \\
\hline \multicolumn{4}{|c|}{$\begin{array}{l}\text { 15. Supplementary Notes } \\
\text { Prepared for the } 22 \text { nd Intersociety Energy Conversion Engineering Conference, } \\
\text { cosponsored by the AIAA, ANS, ASME, SAE, IEEE, ACS, and AIChE, Philadelphia, } \\
\text { Pennsylvania, August } 10-14,1987 \text {. }\end{array}$} \\
\hline \multicolumn{4}{|c|}{$\begin{array}{l}\text { 16. Abstract } \\
\text { A free-piston Stirling engine performance code is being upgraded and validated } \\
\text { at the NASA Lewis Research Center under an interagency agreement between the } \\
\text { Department of Energy's Oak Ridge National Laboratory and NASA Lewis. Many modi- } \\
\text { fications have been made to the free-piston code in an attempt to decrease the } \\
\text { calibration effort. A procedure was developed that made the code calibration } \\
\text { process more systematic. Engine-specific calibration parameters are often used } \\
\text { to bring predictions and experimental data into better agreement. The code was } \\
\text { calibrated to a matrix of six experimental data points. Predictions of the cal- } \\
\text { ibrated free-piston code are compared with RE-1000 free-piston Stirling engine } \\
\text { sensitivity test data taken at NASA Lewis. Reasonable agreement was obtained } \\
\text { between the code predictions and the experimental data over a wide range of } \\
\text { engine operating conditions. }\end{array}$} \\
\hline \multicolumn{4}{|l|}{ 17. Key Words (Suggested by Author(s)) } \\
\hline $\begin{array}{l}\text { Stirling engine; Heat engine; Stirling } \\
\text { cycle; Free-piston Stirling; Computer } \\
\text { model }\end{array}$ & $\begin{array}{l}\text { Unclas } \\
\text { STAR C }\end{array}$ & $\begin{array}{l}\text { d - unlimite } \\
\text { ry } 85\end{array}$ & \\
\hline $\begin{array}{l}\text { 19. Security Classif. (of this report) } \\
\text { Unc las s if fed }\end{array}$ & $\begin{array}{l}\text { spage) } \\
\text { sified }\end{array}$ & $\begin{array}{c}\text { 21. No. of pages } \\
22\end{array}$ & $\begin{array}{r}\text { 22. Price } \\
\mathrm{A} 02\end{array}$ \\
\hline
\end{tabular}

\footnotetext{
*For sale by the National Technical Information Service, Springfield, Virginia 22161
} 